\title{
Increasing of strength of FDM (FFF) 3D printed parts by influencing on temperature-related parameters of the process
}

Vladimir E. Kuznetsov ${ }^{1}$, Alexey N. Solonin, Azamat G. Tavitov, Oleg D. Urzhumtsev, Anna H. Vakulik National University of Science and Technology "MISIS", Moscow, Russia

\begin{abstract}
Current work investigates how user-controlled parameters of 3D printing process define temperature conditions on the boundary between layers of the part being fabricated and how these conditions influence structure and strength of the part. The process studied is fused filament fabrication with a desktop 3D printer and the material utilized is PLA (polylactic acid). As a characteristic of the part strength the fracture load in the case of a three-point bend and calculated related stress were used. During the printing process parts were oriented the long side along the $\mathrm{Z}$ axis, thus, in the bend tests, the maximum stress occurred orthogonally to the layers. During the fabrication process temperature distribution on the samples surface was monitored with thermal imager. Sample mesostructure was analyzed using SEM. The influence of the extrusion temperature, the intensity of part cooling, the printing speed and the time between printing individual layers were considered. The influence of all the parameters can be expressed through two generalizing factors: the temperature of the previous layer and the flow efficiency, determining the ratio of the amount of extruded plastic to the calculated. A regression model was proposed that describes the effect of the two factors on the printed part strength. Along with interlayer bonding strength, these two factors determine the formation of the part mesostructure (the geometry of the boundaries between individual threads). It is shown that the optimization of the process parameters responsible for temperature conditions makes it possible to approximate the strength of the interlayer cohesion to the bulk material strength.
\end{abstract}

Keywords: additive manufacturing; desktop 3D printing; fused deposition modeling; fused filament fabrication; polylactic acid; anisotropy; interlayer bonds; mechanical strength; digital fabrication 


\section{Table of content}

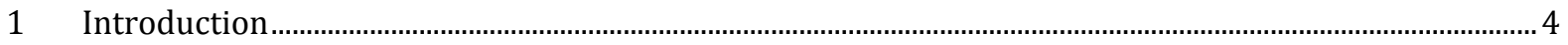

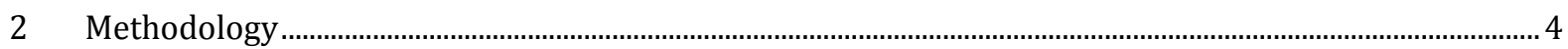

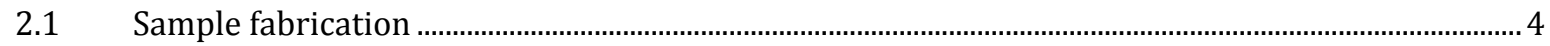

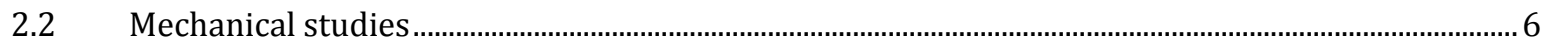

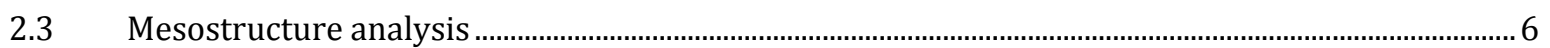

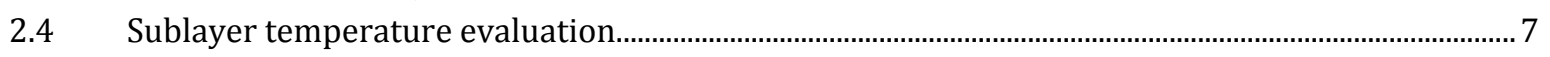

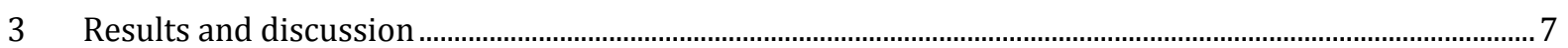

3.1 Extrusion temperature

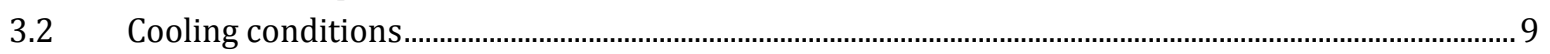

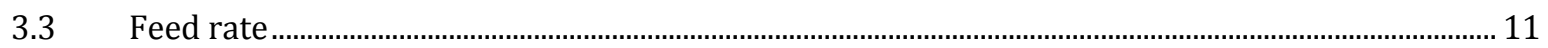

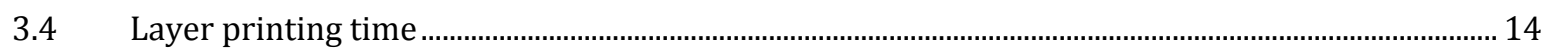

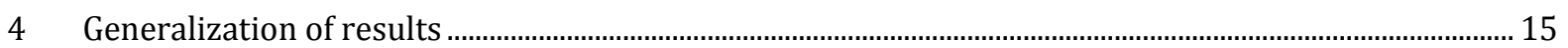

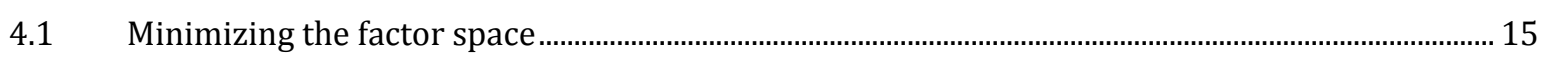

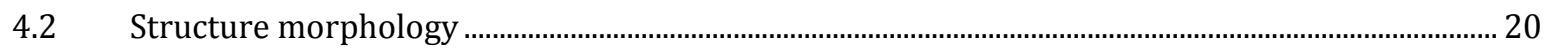

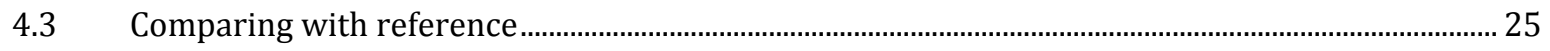

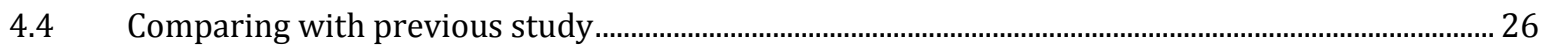

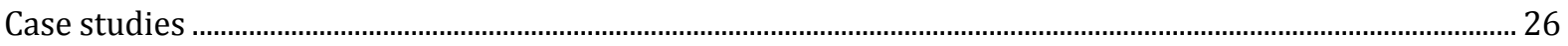

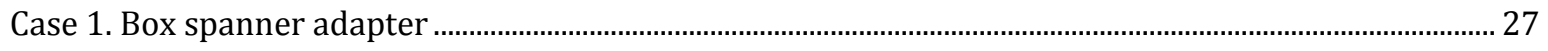

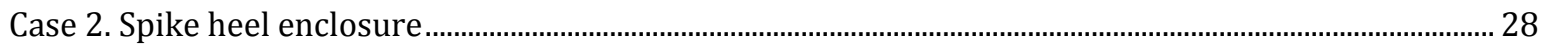

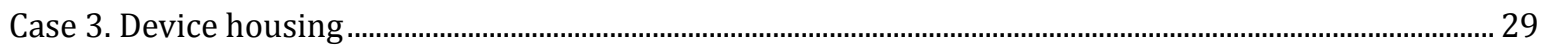

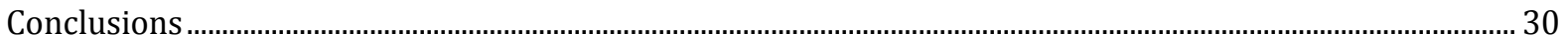

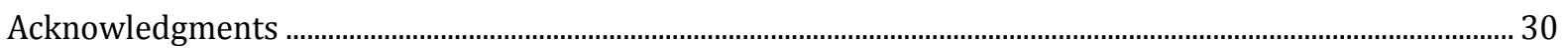

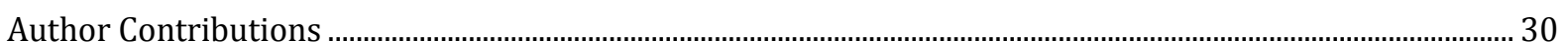

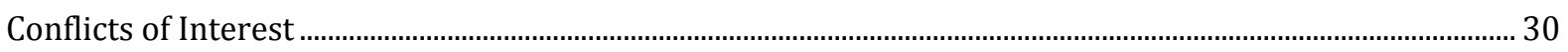

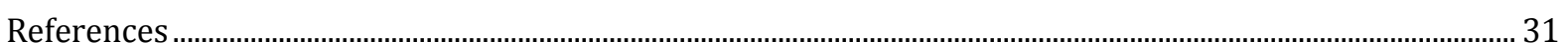


In current work, the following notions are introduced and the following shorthands are used:

FDM(FFF) - Fused Deposition Method (Fused Filament Fabrication) is a technology of digital additive manufacturing based on layered deposition of melted thermoplastic. While FDM is a trademark of Stratasys Inc., the FFF is a term coined inside the RepRap community;

$U F L$ - Ultimate Fracture Load, maximum load observed during mechanical testing;

UFS - Ultimate Fracture Strength, calculated stress in the sample caused by UFL;

$t_{E}$ - extrusion temperature - temperature of the hot end of the 3D printer at which sample is fabricated; Sublayer - a layer of plastic already deposited by $F D M(F F F) 3 D$ printer which acts as a substrate for layer being deposited at given moment;

$t_{\text {SUB }}$ - temperature of sublayer;

Filament — plastic in the filament form used as supply in FDM(FFF) process;

Thread - extruded and deposited thread of plastic mimicking the 3D printed part;

Underextrusion - a characteristic defect in $F D M(F F F)$ process resulting in significant drop in thread thickness or in thread interruptions;

$F_{E}$ - flow efficiency - a ratio of real to calculated mass of 3D printed object;

$S E M$ - scanning electron microscopy;

$D S C$ - differential scanning calorimetry. 


\section{Introduction}

Parts obtained with a 3D printer tend to be far inferior in strength to the usual plastic products obtained with the help of injection molding and other conventional manufacturing methods. One of the reasons for the low strength is the lack of knowledge about the effect of the FDM (FFF) process parameters available for operator control on the strength of the resulting part. In the area of FDM (FFF) 3D printing, there should be no notion of "strength of the part material", just the "part strength" is important. Products obtained with this technology are extremely anisotropic [1] and consist of layers (usually of the same thickness), which in turn are patterns formed by a thread made of the molten polymer [2-4]. The failure of a loaded part occurs in the vast majority of cases along the boundary between the threads. The part strength is accordingly determined by its geometric parameters (the superposition of the individual threads relative to each other) and the bond strength between the individual threads. A good illustration that the strength of the material itself is of secondary importance for the part strength obtained with FDM (FFF) is shown in [5], where the part strength for ABS products is significantly inferior to the strength of PLA parts, while parts obtained from the same materials with injection molding demonstrate the directly opposite picture.

Temperature conditions at which a bond is formed between the layers play obviously an important role in strengthening the junction [6, 7]. However, the temperature parameters of the 3D printing process on an average desktop printer with an open working volume (without an insulated thermal camera) are not so easy to register and control. The purpose of this study is to find and evaluate the user-accessible desktop FDM (FFF) 3D printer capabilities to increase the strength of PLA printed parts associated with temperature factors. There are various factors associated with the geometric parameters of the part and process (nozzle diameter, layer thickness) left aside, as well as the characteristics of the material used for printing.

\section{Methodology}

As of now, there are no standard and widely accepted methods for determining the strength of FDM (FFF) parts. That fact allows researchers to enjoy certain freedom in choosing the geometry of the test sample and the way to apply load to it. However, most of the known works [8-15] on the dependence of FDM (FFF) parts strength from certain parameters are based on the techniques described by the standard [16], developed for testing isotropic materials. In our opinion, a simple and informative technique for evaluating the strength of a part obtained with FDM (FFF) is a three-point bending until the sample is broken [17]. The shape and dimensions of the sample must ensure its stability in the printing process with a long-side orientation along the $\mathrm{Z}$ axis. Such an orientation of the sample during printing leads to the fact that the maximum stresses acting in the critical section are oriented orthogonally to the layer boundaries, that is, in the direction in which the product should exhibit the least strength. Testing of samples with stresses applied along fibers has less practical interest, since an anisotropic part will obviously exhibit higher strength characteristics along the fibers.

\subsection{Sample fabrication}

For this experiment we used tube-shaped samples of rectangular cross-section with $10 \times 20 \mathrm{~mm}$ in size, of $120 \mathrm{~mm}$ in length with fillets R2 $\mathrm{mm}$ along long ribs (Figure 1, left). The tube shape of the sample was provided by setting the "infill" parameter to " 0 " in the slicer interface program (Cura 15.04) [18] and turning off the "solid infill top" and "solid infill bottom" checkboxes. The thickness of the tube wall was defined by the "shell thickness" parameter and was set to $2.4 \mathrm{~mm}$. The choice of this exact shape and sample size is determined by the desire to obtain data compatible with the one from recent research on the main geometric parameters (nozzle diameter and layer thickness) influence on printed part strength [17]. For the production of samples, the Ultimaker 2 (Ultimaker B.V., Geldermalsen, The Netherlands) 
desktop printer was used. The machine was equipped with few aftermarket upgrades, such as alternative BondTech (Bondtech AB, Värnamo, Sweden) extruder [19], built on the basis of a stepper motor with an integrated gearbox and double drive (both feed gears are driven) and an alternative hot end from 3D Solex (Cepta AS, Norway) [20] with heating element of increased power $(\sim 50 \mathrm{~W})$. The heating unit, compared to the standard one installed on the Ultimaker 2 , allows changing the nozzles. In this series of experiments a nozzle with a channel diameter of $0.6 \mathrm{~mm}$ was used instead of the standard $0.4 \mathrm{~mm}$ nozzle for Ultimaker 2.

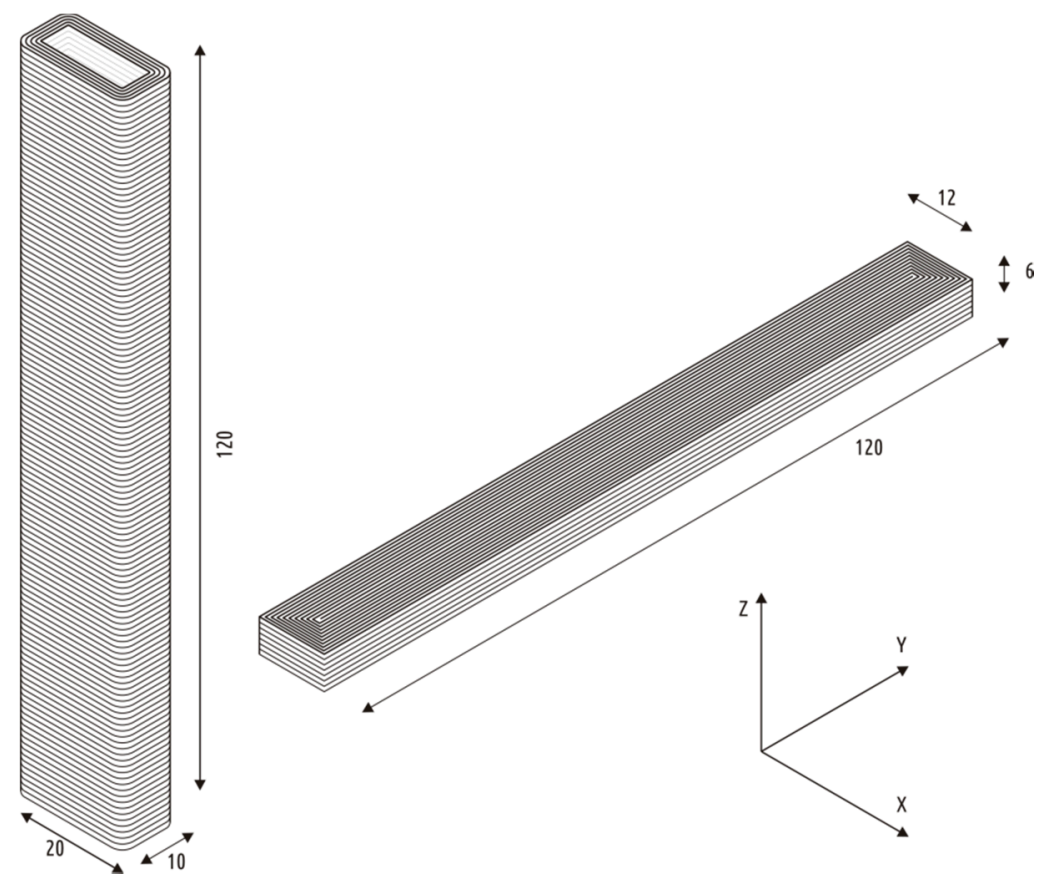

Figure 1. Shape, dimensions and printing orientation of the research (left) and the reference (right) samples

The turquoise PLA filament from REC brand was used. In different parts of the experiment filament from different lots might have been used, which can introduce errors or deviations into the study. The choice of this specific plastic is due solely to the desire to work with locally produced material. In the course of experiments, the following parameters of sample manufacturing remained unchanged:

- nozzle diameter and layer thickness ( 0.6 and $0.3 \mathrm{~mm}$, respectively);

- bed heating temperature $\left(60^{\circ} \mathrm{C}\right)$.

The following parameters were varied:

- hot end temperature (from 190 to $250^{\circ} \mathrm{C}$ with $10^{\circ} \mathrm{C}$ step);

- cooling intensity (the parameter "fan speed" that defines fresh layer cooling was set to $0 \%, 50 \%$, $100 \%$ );

- linear printing speed (feed rate $12.5,25,37.5$, and $50 \mathrm{~mm} / \mathrm{s}$ ), and

- the number of simultaneously printed samples $(1,2,3$ or 5$)$.

For each of the observations, a lot of at least three samples was prepared and tested to perform averaging and exclude outliers.

The data on PLA plastic part strength vary largely in literature, which makes it difficult to use them for comparison. Thus, specially manufactured samples of parallelepiped shape with dimensions of $6 \times 12 \times 120$ $\mathrm{mm}$ were used to estimate reference strength values. Printing was performed out of the same material, with the same nozzle $(0.6 \mathrm{~mm})$ and layers of the same thickness $(0.3 \mathrm{~mm})$, however the reference samples were oriented with the long side along the " $\mathrm{Y}$ " axis (Figure 1, right). Thus, in the bending tests, the maximum stress acted parallel to the constituting threads. Obviously, for such shape and loading 
method, the fiber strength is of greatest importance rather than cohesion strength between them. To ensure that all threads are directed along the axis where maximum stresses occur, the upper and lower bases thickness was set to zero and the wall thickness was set equal to the part width (i.e. the whole sample consisted of a shell, with no infill and top/bottom covers). Reference samples were printed at $210^{\circ} \mathrm{C}$, with fans switched on at maximum intensity, and $25 \mathrm{~mm} / \mathrm{s}$ feed rate.

\subsection{Mechanical studies}

The printed samples were tested with a universal electromechanical testing machine with a test rig for three-point bending. The samples rested on two cylindrical supports of $30 \mathrm{~mm}$ diameter with a distance of $100 \mathrm{~mm}$ between the centers, the load was put on the middle of the sample between the supports by a cylinder of $40 \mathrm{~mm}$ in diameter.

The tests were carried out with the crosshead of the tensile tester moving at a speed of $10 \mathrm{~mm} / \mathrm{min}$. During the test, the displacement and load were recorded, with the initial load for stabilizing the sample set at $5 \mathrm{~N}$. The key parameter was the maximum load measured before the samples failed (UFL).

For a more general discussion of results obtained, the normal stresses in the samples at the moment of failure (UFS) were calculated. The stresses were calculated by dividing the maximum moment $(M)$ by the section modulus $(W)$ :

$$
U F S=\frac{M}{W^{\prime}} M P a .
$$

The maximum moment for testing samples at distance between the supports $(I)$ of $100 \mathrm{~mm}$

$$
M=\frac{F \times l}{4}=0.025 F, N \cdot m,
$$

where $F$ is the load in $\mathrm{N}$ at the moment of failure (UFL).

The section moment is calculated by using formula:

$$
W=\frac{2 I}{h}, m^{3},
$$

where $I$ is the second moment of the cross-section, calculated with the built-in app of SolidWorks to be $1416.89 \mathrm{~mm}^{4}$.

Thus, the maximum normal stress in the sample can be calculated from the load by

$$
U F S=0.088 F,
$$

where $F$ is given in $\mathrm{N}$ and $U F S$ is in MPa.

For reference samples with rectangular cross-section stresses were calculated by classical formula:

$$
U F S=\frac{3 F \times l}{2 b \times h^{2}},
$$

where $F$ is maximum observed load (UFL), $\mathrm{N} ; l$ is a support span and $b$ and $h$ are wideness and thickness of the sample, $m$

For the reference sample of used geometry:

$$
U F S=0.347 F \text {, }
$$

where $F$ is given in $\mathrm{N}$ and $U F S$ is in MPa.

\subsection{Mesostructure analysis}

Cross-section mesostructure of some of the broken samples were investigated using scanning electron microscopy (SEM) on Tescan Vega 3 LMH (TESCAN Brno, s.r.o., Brno - Kohoutovice, Czech Republic) microscope. 


\subsection{Sublayer temperature evaluation}

During the samples printing, the temperature distribution over the surface of the sample was recorded using a FLIR B335 (FLIR Systems, Wilsonville, OR, USA) thermal imager with a resolution of $320 \times 240$ pixels. The camera was located in front of the printer. Thermal imaging was carried out when the sample was ready for $40-60 \%$ (approximately in the area in which further destruction at the three-point bend occurred). The survey was carried out with a distance of about $30 \mathrm{~cm}$, which is equal to minimal focal distance documented for the imager.

The software "FLIR Tools" [21] used to determine the average temperature on the surface of the sample at a distance of $1 . . .3 \mathrm{~mm}$ from the lower cut of the nozzle. This temperature was taken as the sublayer temperature $\left(t_{\text {SUB }}\right)$.

\section{Results and discussion}

\subsection{Extrusion temperature}

The default $t_{E}$ for the PLA in the Ultimaker 2 printer is $210^{\circ} \mathrm{C}$. Filament producers generally do not indicate the specific $t_{E}$, but the suggested temperature range. In particular, for the material used in the study, the manufacturer claims a range of 190 to $230^{\circ} \mathrm{C}$.

DSC analysis of the initial filament (Figure 2) allows to reveal the glass transition and melting temperatures of the polymer, which are, respectively, $70^{\circ} \mathrm{C}$ and $151^{\circ} \mathrm{C}$, which corresponds to the known reference values for PLA. In the range between $190^{\circ} \mathrm{C}$ and $250^{\circ} \mathrm{C}$, there are no qualitative changes in the curve, which allows one to expect that the dependency of the strength characteristics on the temperature in this interval will have be continuous. Moreover, there are no obvious obstacles for printing at temperatures exceeding the manufacturer's established limit of $230^{\circ} \mathrm{C}$, leaving aside such aspects like increase in the embodied energy of the product, the possible increase in ultrafine particles emission and the reduction in the service life of non-metallic parts of the hot end.

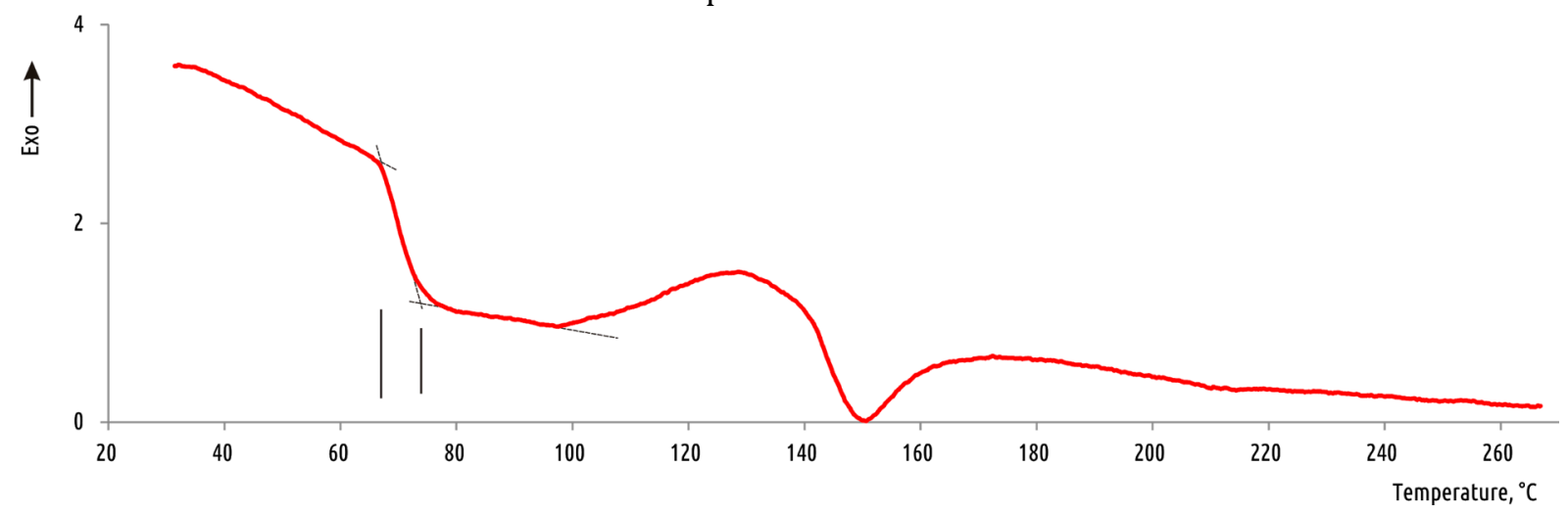

Figure 2. DSC analysis of filament used for samples fabrication

In the study the $t_{E}$ was set directly on the printer at the beginning of the printing cycle. The temperature is monitored with the PT100 temperature sensor installed inside the heating unit. It should be noted that the actual temperature of the plastic being pressed through the nozzle may differ from the temperature of the heating block (from the temperature on the temperature sensor) in a negative way and this difference may increase when increasing volume of plastic delivered through the nozzle per unit time.

Samples printed at $190^{\circ} \mathrm{C}$ contained visible underextrusion defects and were thus excluded from further tests and the analysis. Samples obtained by printing in the temperature range of $200 \ldots 250^{\circ} \mathrm{C}$ showed an explicit dependence of the strength on $t_{E}$. In all the investigated range, the strength increases with increasing temperature (Figure 3 ). 


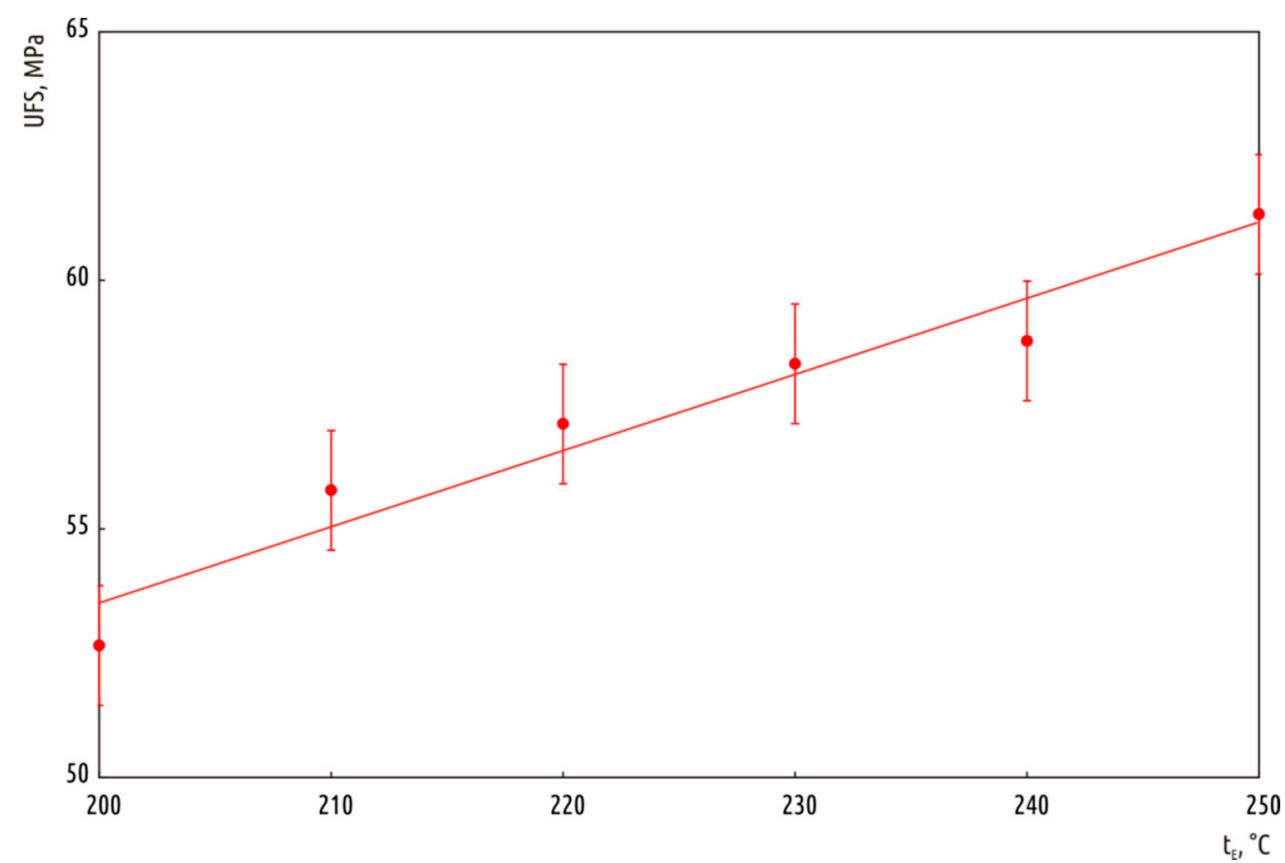

Figure 3. Dependence of the extrusion temperature on the samples strength

The increase in the $t_{E}$ is also reflected in the growth of the sample mass (Figure 4).

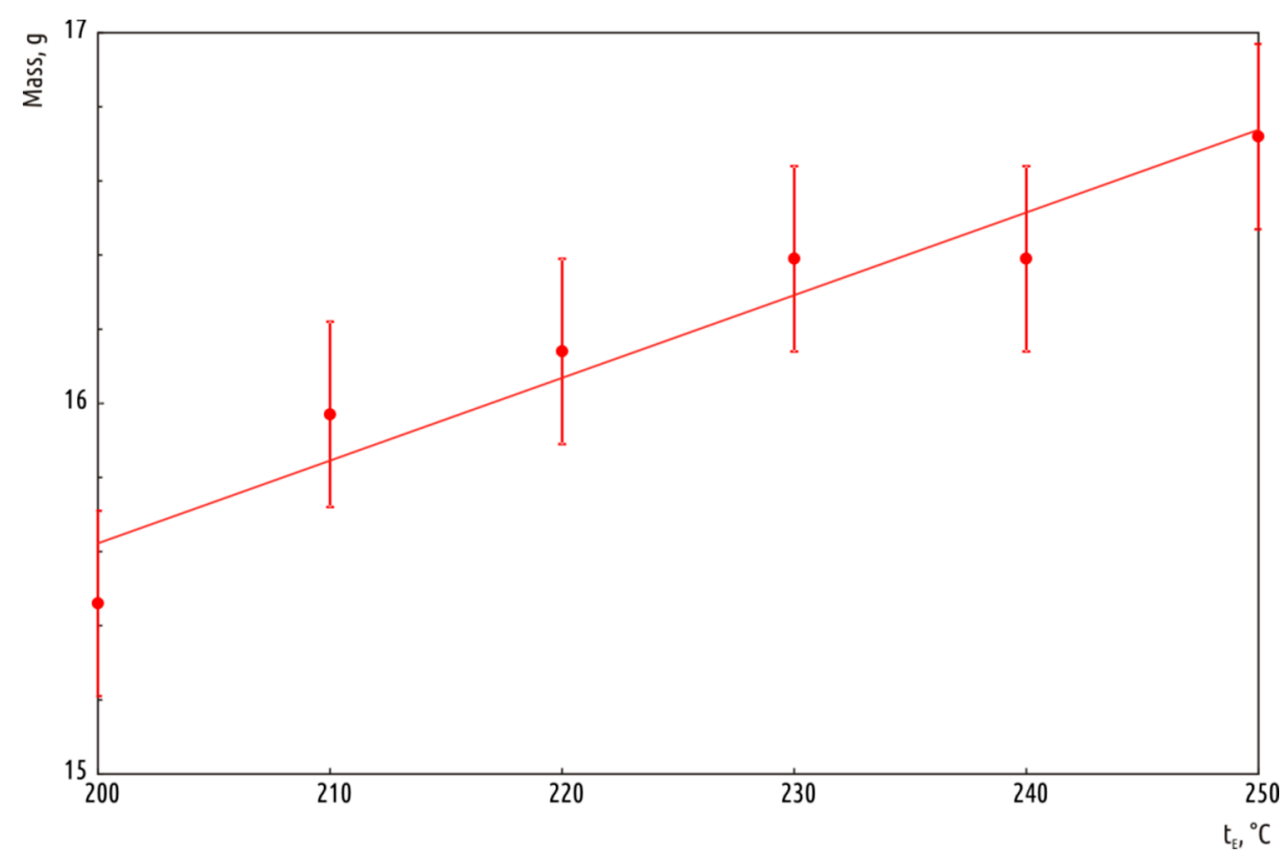

Figure 4. Dependence of the extrusion temperature on the samples mass

This increase is explained by the growing fluidity of superheated liquid plastic and the decrease in resistance as it passes through the channel in the nozzle (extrusion resistance). Despite the fact that the rotation speed of the extruder motor does not depend on the temperature of the heating element, extrusion resistance decreases with increasing temperature, so that the plastic passes faster through the feeder due to decrease in parasitic slides and filament strains.

The increase in the sample mass should have a positive effect on its strength, however, when the $t_{E}$ is changed from $200{ }^{\circ} \mathrm{C}$ to $250{ }^{\circ} \mathrm{C}$, the average mass of the sample increased by $8 \%$, while the strength increased by $16 \%$.

The increase in the $t_{E}$ is also accompanied by a noticeable increase in the $t_{S U B}$ (Figure 5 ). 


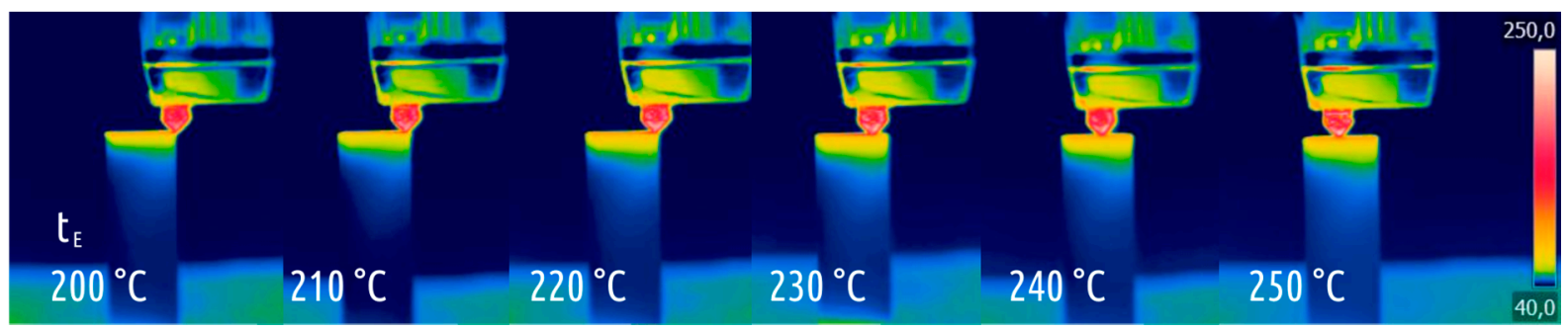

Figure 5. Temperature distribution in samples printing at different $t_{E}$ (collage of six different thermograms)

Analysis of the longitudinal sections of the samples using SEM shows that the increasing flow of liquid plastic with increasing temperature does not fundamentally change the structure of the boundaries between the individual threads forming the sample. The interlayer boundaries are still weakened due to discontinuities, which are present along the boundaries of the individual threads forming each layer (Figure 6).
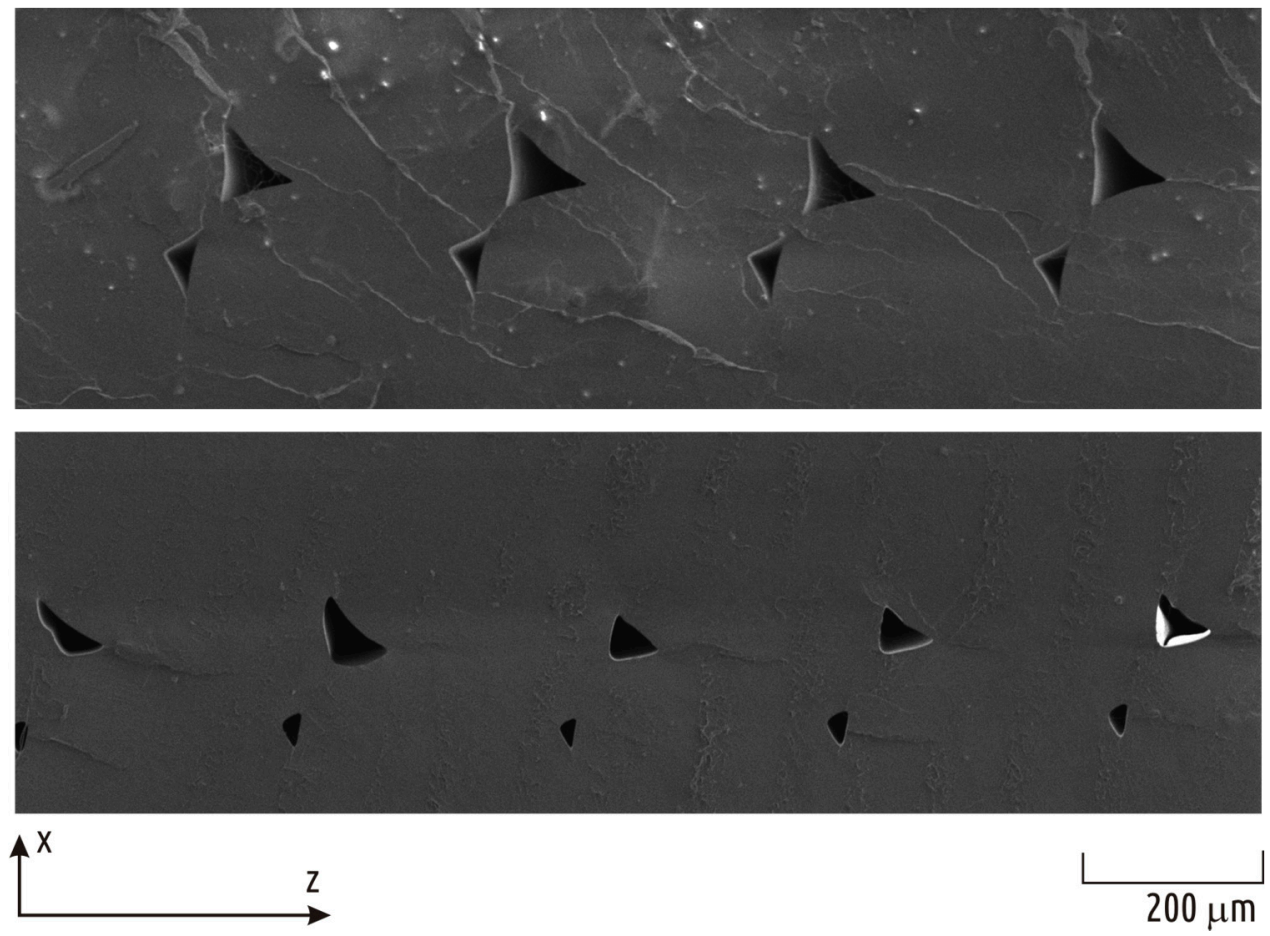

Figure 6. Voids between threads constituting samples printed at $210^{\circ} \mathrm{C}$ (above) and $250^{\circ} \mathrm{C}$ (below)

At the same time, voids on a sample made at elevated temperature have smaller area.

The increase in the strength of the samples with increasing temperature is double-natured. In addition to changing the mass off the sample and, subsequently, geometry of the interlayer boundaries, the strength increases due to an increase in cohesion between layers, depending on the temperature conditions for the formation of the boundary between the new and the previous layer. It is impossible to distinguish the impact of these two strengthening mechanisms. The next experiment was held to exclude any significant mass variations.

\subsection{Cooling conditions}

For the next set of experiments another group of sample lots was fabricated. Two levels of $t_{E}$ were tested, the default of $210^{\circ} \mathrm{C}$ and the elevated of $250^{\circ} \mathrm{C}$; samples were printed with different cooling conditions. Part cooling is set with the "fan speed" parameter in most desktop 3D printers, which defines fan rotation speed in percent ( $0 \%$ means the fans are off, $100 \%$ means they operate at full speed). Varying fan speed did not have any significant effect on sample mass, but obviously influenced the $t_{S U B}$ (Figure 7). 


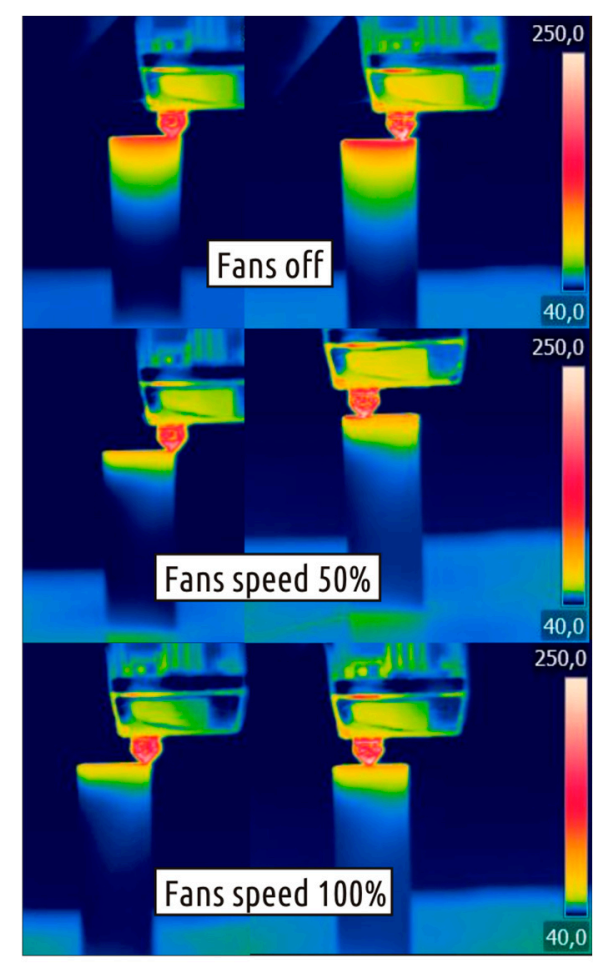

$$
210^{\circ} \mathrm{C} \quad 250^{\circ} \mathrm{C}
$$

Figure 7. Temperature distribution depending on air flow (fans speed)

The experiment showed a strong dependency between part strength and cooling conditions (Figure 8). Strength of tested samples printed at default and elevated $\left(210\right.$ and $\left.250^{\circ} \mathrm{C}\right)$ temperature was increased by $11 \%$ and $12 \%$, accordingly, by simply disabling the cooling.

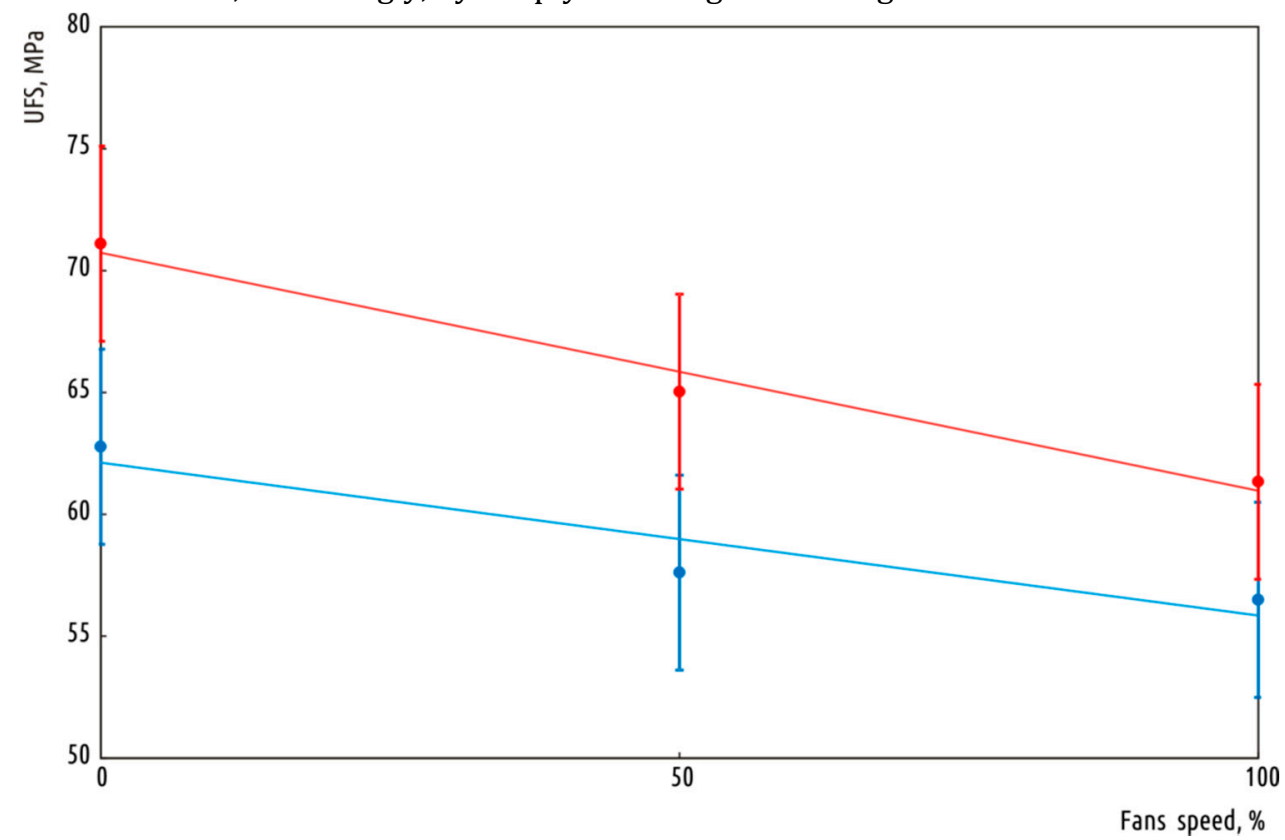

Figure 8. Dependence of cooling conditions (fans speed) on samples strength

Figure 9 contains SEM scans of longitudinal cross sections of samples, printed at $t_{E}$ of $210^{\circ} \mathrm{C}$ with fans speed of $100 \%, 50 \%$ and with fans off. 


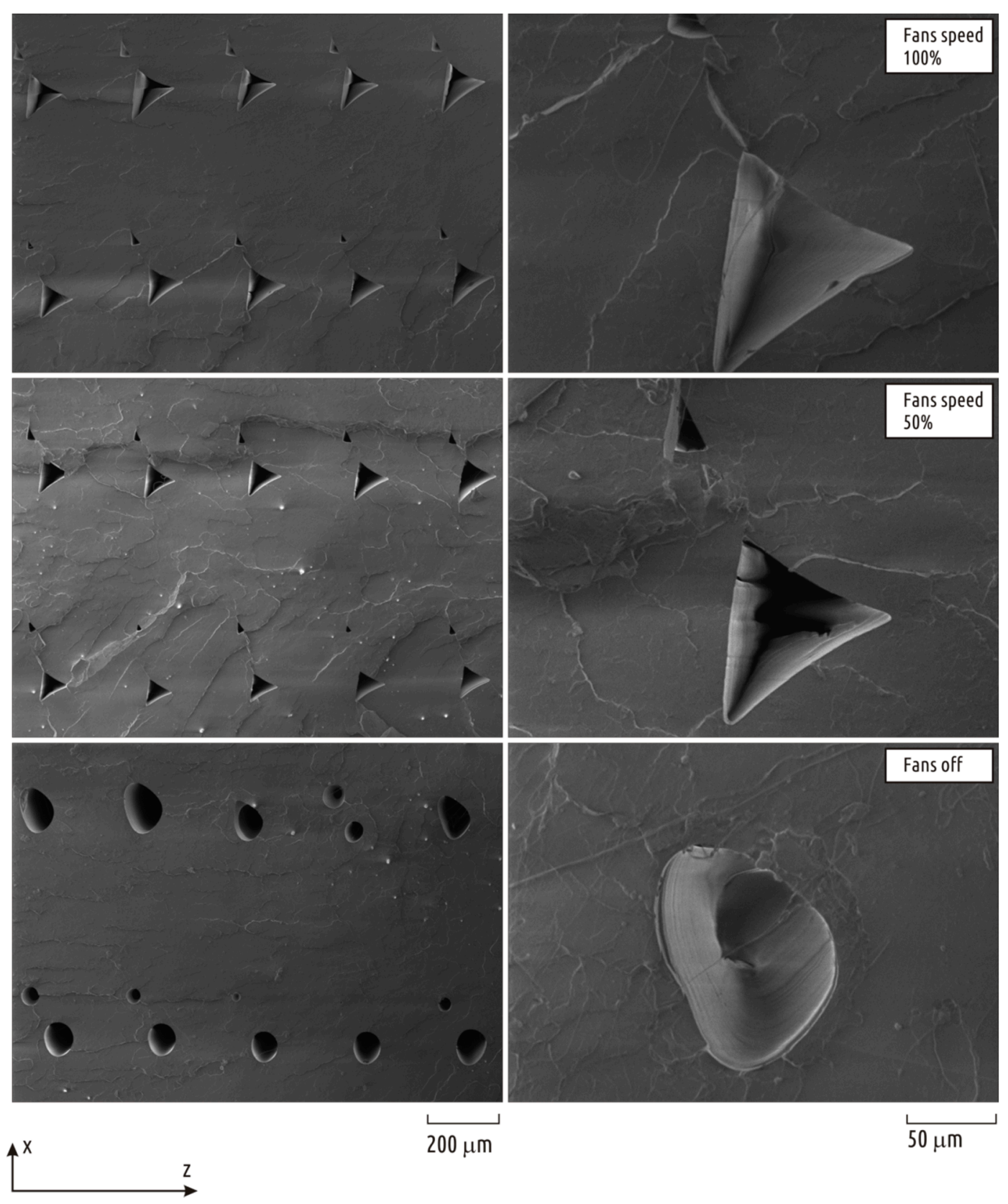

Figure 9. Mesostructure of samples printed with different cooling conditions

The cross-section of the sample printed with the fan off (the bottom image) looks totally different from the samples printed with the fan set at $50 \%$ and $100 \%$ (middle and upper images). Triangular cavities between the individual threads become more rounded when fans are switched off.

From a practical standpoint, increasing sample strength by turning off the fans has limited applicability. Obviously, results obtained for samples of such a low cross-section will differ a lot from those obtained for bigger ones. Printing time for samples of given geometry was $\sim 7$ seconds per layer, and the next layer was deposited while the previous one was still hot. The longer the layer is printed, the colder the underlying one will become.

\section{3 $\quad$ Feed rate}

Linear printing speed (feed rate) can have the least predictable effect on layer cohesion strength out of all factors considered in this paper. On one hand, increasing linear velocity also leads to an increase in the volumetric printing speed (flow rate, the volume of plastic extruded through the nozzle per unit of time). Thus, with increasing printing speed, the resistance to extrusion increases, which, obviously, will 
adversely affect the part mass. Moreover, without changing the temperature of the heating block, increasing the flow rate can lead to a decrease in the temperature of the plastic at the nozzle outlet - the plastic can be fed through the hot end so quickly that it will be able to melt, but will not be able to heat up to the temperature of the heating block due to lower exposure time.

On the other hand, the higher the printing speed, the sooner the next layer is printed and the less the sublayer cools before new layer is deposited. In this sense, increasing the printing speed can have a similar effect to decreasing cooling intensity and, thus, it will contribute to an increase in the cohesion strength between the layers. To study the influence of such a contradictory factor, one more experiment was conducted. During sample fabrication, the $t_{E}$ (the default one of $210{ }^{\circ} \mathrm{C}$, and the elevated of $250^{\circ} \mathrm{C}$ ) and feed rate were varied. Samples were printed at a speed of $12.5,37.5$ and $50 \mathrm{~mm} / \mathrm{s}$. In this case, samples printed at a temperature of $210^{\circ} \mathrm{C}$ at a speed of $50 \mathrm{~mm} / \mathrm{s}$ contained obvious underextrusion defects and were excluded from the analysis. Strength tests of the remaining samples showed the following. Despite the fact that the mass of samples predictably decreases with increasing printing speed (Figure 10), the strength of samples printed at a temperature of $250^{\circ} \mathrm{C}$ increases (Figure 11).

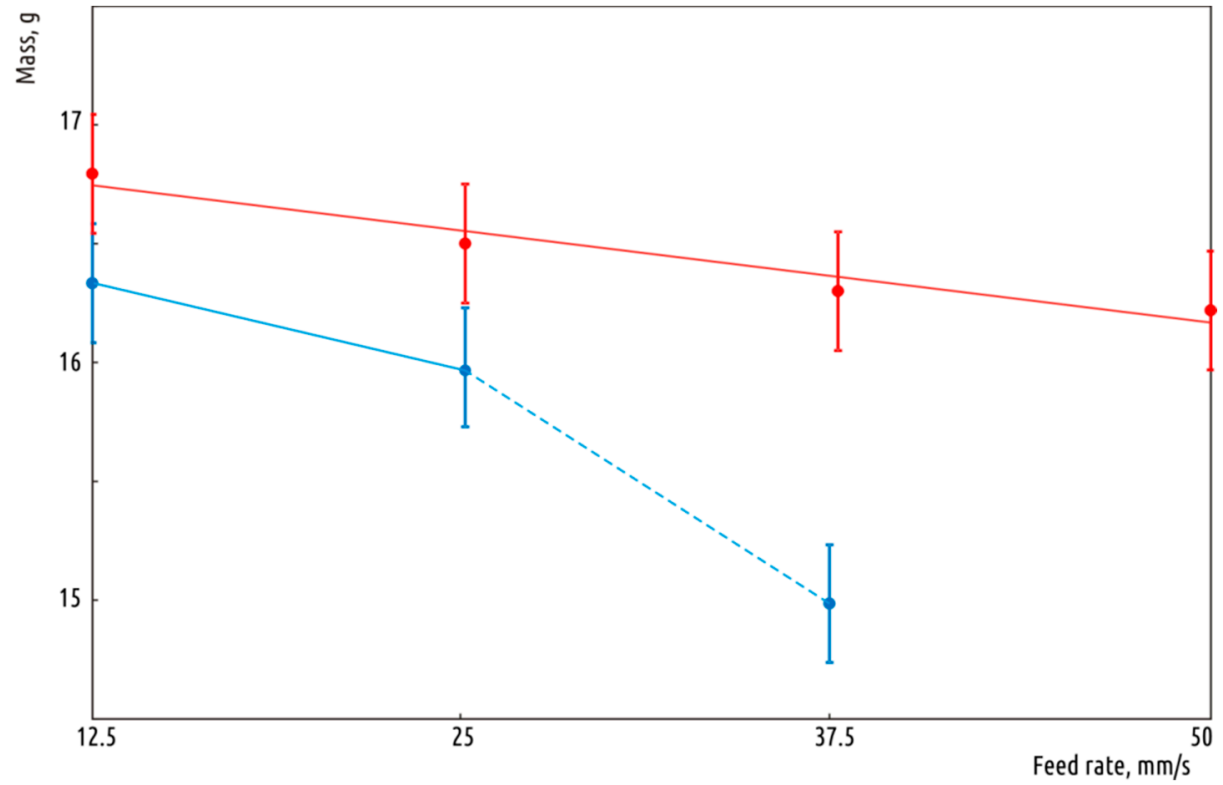

Figure 10. Dependence of printing speed on sample mass for $210^{\circ} \mathrm{C}$ (blue) and $250^{\circ} \mathrm{C}$ (red) extrusion 


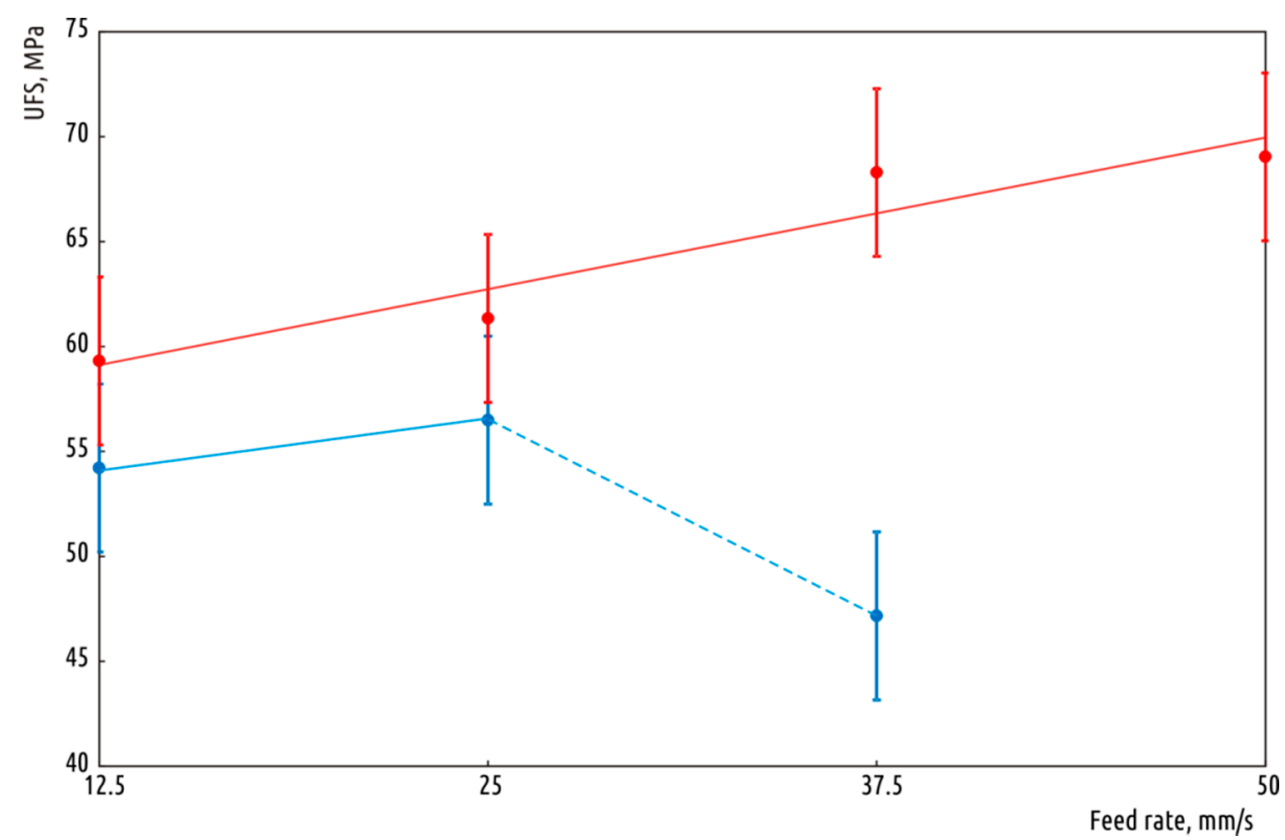

Figure 11. Dependence of printing speed on samples strength for $210{ }^{\circ} \mathrm{C}$ (blue) and $250{ }^{\circ} \mathrm{C}$ (red)

For samples printed at the default temperature $\left(210^{\circ} \mathrm{C}\right)$, the picture is different. If one can see a certain increase in strength when moving from a speed of 12.5 to a speed of $25 \mathrm{~mm} / \mathrm{s}$, then a further increase in speed to $37.5 \mathrm{~mm} / \mathrm{s}$ leads to a sharp drop. The Figure 11 reflects the duality of the effect of printing speed on the part strength. At a temperature of $250^{\circ} \mathrm{C}$, the plastic had sufficient fluidity to uniformly extrude at a speed of up to $9 \mathrm{~mm}^{3} / \mathrm{s}$ (volumetric velocity at a feed rate of $50 \mathrm{~mm} / \mathrm{s}$ ), but at a lower temperature, such a high speed led to the formation of obvious defects (specimens excluded from the study). Printing at $210^{\circ} \mathrm{C}$ at a speed of $6.8 \mathrm{~mm}^{3} / \mathrm{s}(37.5 \mathrm{~mm} / \mathrm{s}$ feed $)$ probably resulted in the appearance of defects not identifiable visually, but dramatically reducing the strength of the sample.

In general, despite the optimistic results obtained at $t_{E}$ of $250^{\circ} \mathrm{C}$, when significant growth of UFS was achieved with a quadrupled speed (and corresponding reduction in printing time), printing speed has very limited potential for controlling the part strength. As noted above, the increase in strength is provided by increasing the $t_{S U B}$ by reducing the time intervals between printing adjacent layers (Figure 12).
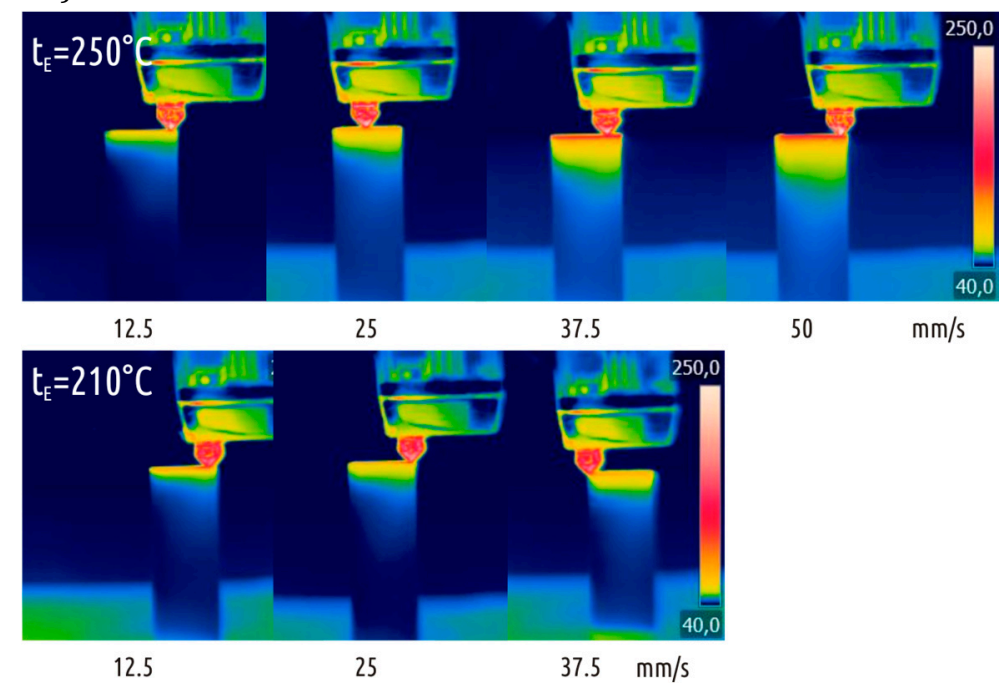

Figure 12. Temperature distribution depending on printing speed (feed rate)

Obviously, this effect will be differently exhibited when printing parts with different perimeter length. In the case of relatively small parts (like the samples used in this study), a reasonable increase in speed will 
lead to a noticeable increase in $t_{\text {Sив }}$ and, as a result, a noticeable increase in strength. When printing much larger objects, where single layer printing time will not be counted in seconds but in tens of seconds or minutes regardless of the printing speed, the $t_{S U B}$ will be close to the ambient temperature, leading the effect on strength to zero (or to negative due to mass reduction). To prove that statement, the next experiment was conducted.

\subsection{Layer printing time}

There were two, three and five samples sent to be printed with the strategy set to "all at once". Two values of $t_{E}$ were used of $210^{\circ}$ and $250^{\circ} \mathrm{C}$ as well as constant printing speed of $25 \mathrm{~mm} / \mathrm{s}$.

Increasing the number of samples on the bed did not lead to variations in their mass, but resulted in the increase in the time between printing the layers $(\sim 6.7,15.5,23.6$ and 39.7 seconds for one, two, three and five samples, respectively) and, as a consequence, to the drop in $t_{S U B}$ (Figure 13). The latter had a noticeable effect on the strength of the samples (Figure 14).

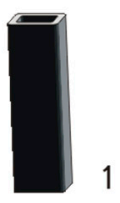

$\mathrm{t}_{\mathrm{E}}=250^{\circ} \mathrm{C}$

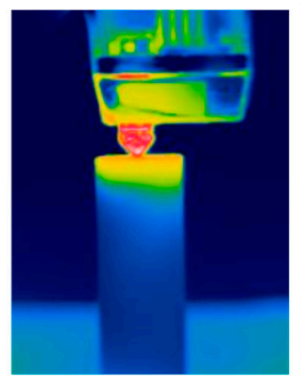

1

$\mathrm{t}_{\mathrm{E}}=210^{\circ} \mathrm{C}$

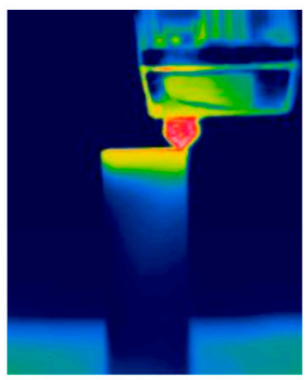

1

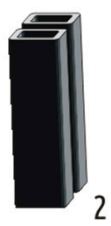

2

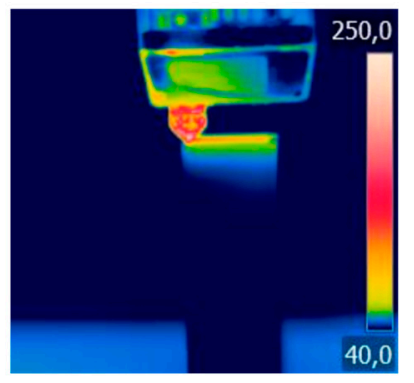

2

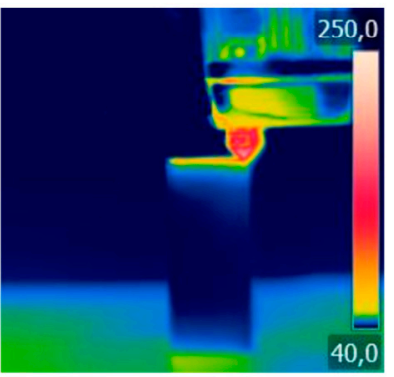

2

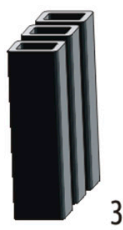

3

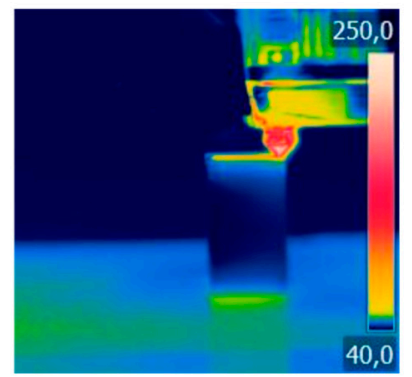

3

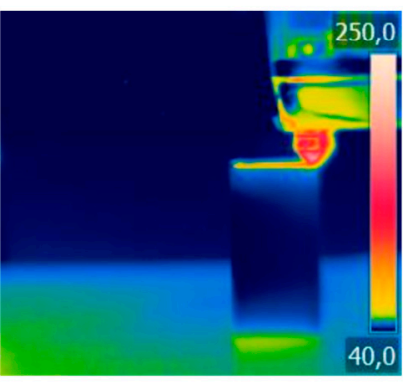

3
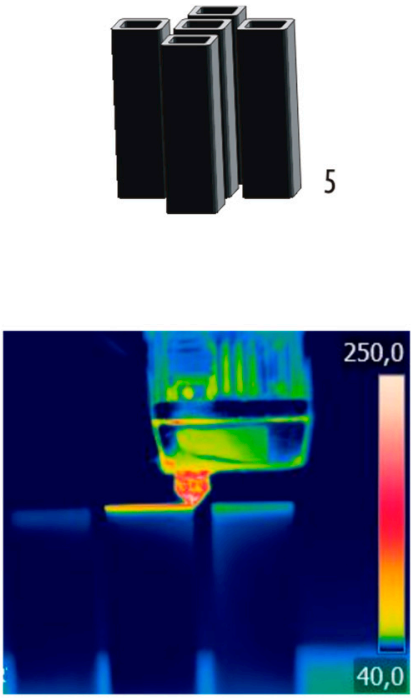

5

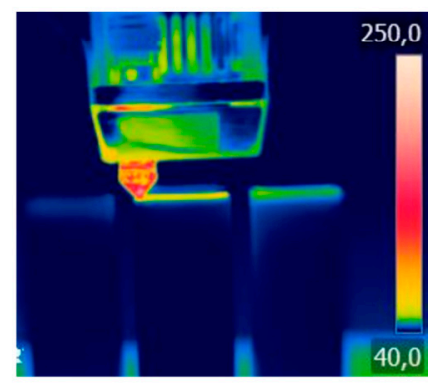

5

Number of samples printing at the same time

Figure 13. Positioning of samples (upper row) and temperature distribution at printing 1, 2, 3 and 5 samples at the same time 


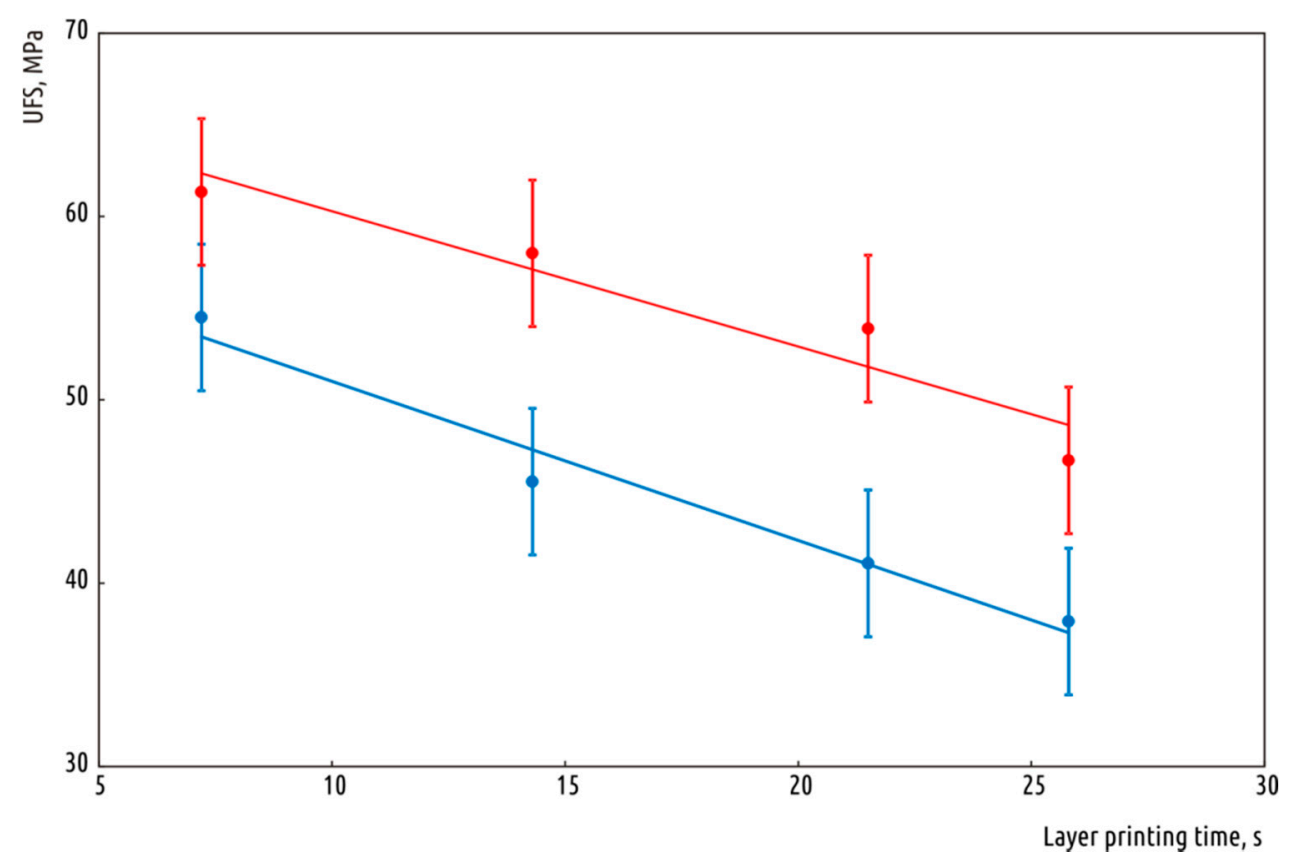

Figure 14. Dependence of layer printing time on sample strength for $210^{\circ} \mathrm{C}$ (blue) and $250^{\circ} \mathrm{C}$ (red) prints

\section{Generalization of results}

\subsection{Minimizing the factor space}

In order to generalize results above, the following statements can be done. The 3D printed part strength increases with the increase in $t_{E}$, with a decrease in the cooling intensity and with a reduction in the time interval between individual layers (when rejecting to print simultaneously several parts or due to a reasonable increase in printing speed). Table 1 contains experimental data of all sample lots tested with rows arranged by $t_{s u b}$ ascending. The Figure 15 shows a scatter plot in UFS - $t_{S U B}$ coordinates, which combines averages on all the observations of this study. 
Table 1. Experimental data

\begin{tabular}{|c|c|c|c|c|c|c|c|c|c|}
\hline Lot \# & Key & $\begin{array}{l}\boldsymbol{t}_{E}, \\
{ }^{\circ} \mathrm{C}\end{array}$ & $\begin{array}{l}\text { Feed rate, } \\
\mathrm{mm} / \mathrm{s}\end{array}$ & $\begin{array}{l}\text { Fan speed, } \\
\%\end{array}$ & n* & $\begin{array}{l}\text { Mass, } \\
\text { g }\end{array}$ & $\begin{array}{l}t_{S U B}, \\
{ }^{\circ} \mathrm{C}\end{array}$ & $F_{E}$ & $\begin{array}{l}\text { UFS, } \\
\text { MPa }\end{array}$ \\
\hline 1 & t210f25c100n5 & 210 & 25 & 100 & 5 & 15.72 & 41 & 0.898 & 37.9 \\
\hline 2 & t250f25c100n5 & 250 & 25 & 100 & 5 & 16.43 & 41 & 0.939 & 46.7 \\
\hline 3 & $\mathrm{t} 210 \mathrm{f} 25 \mathrm{c} 100 \mathrm{n} 3$ & 210 & 25 & 100 & 3 & 15.77 & 48 & 0.901 & 41.1 \\
\hline 4 & $\mathrm{t} 210 \mathrm{f} 25 \mathrm{c} 100 \mathrm{n} 2$ & 210 & 25 & 100 & 2 & 15.81 & 54 & 0.903 & 45.5 \\
\hline 5 & $\mathrm{t} 250 \mathrm{f} 25 \mathrm{c} 100 \mathrm{n} 3$ & 250 & 25 & 100 & 3 & 16.44 & 60 & 0.939 & 53.9 \\
\hline 6 & t210f13c100n1 & 210 & 12.5 & 100 & 1 & 16.33 & 61 & 0.933 & 54.2 \\
\hline 7 & t250f13c100n1 & 250 & 12.5 & 100 & 1 & 16.79 & 68 & 0.960 & 59.3 \\
\hline 8 & $\mathrm{t} 200 \mathrm{f} 25 \mathrm{c} 100 \mathrm{n} 1$ & 200 & 25 & 100 & 1 & 15.46 & 69 & 0.883 & 52.6 \\
\hline 9 & $\mathrm{t} 250 \mathrm{f} 25 \mathrm{c} 100 \mathrm{n} 2$ & 250 & 25 & 100 & 2 & 16.50 & 70 & 0.943 & 58.0 \\
\hline 10 & $\mathrm{t} 210 \mathrm{f} 25 \mathrm{c} 100 \mathrm{n} 1$ & 210 & 25 & 100 & 1 & 15.97 & 73 & 0.913 & 56.3 \\
\hline 11 & $\mathrm{t} 220 \mathrm{f} 25 \mathrm{c} 100 \mathrm{n} 1$ & 220 & 25 & 100 & 1 & 16.14 & 74 & 0.922 & 57.2 \\
\hline 12 & t230f25c100n1 & 230 & 25 & 100 & 1 & 16.39 & 77 & 0.937 & 58.0 \\
\hline 13 & t210f38c100n1 & 210 & 37.5 & 100 & 1 & 14.85 & 77 & 0.848 & 47.2 \\
\hline 14 & t240f25c100n1 & 240 & 25 & 100 & 1 & 16.39 & 78 & 0.937 & 59.1 \\
\hline 15 & $\mathrm{t} 210 \mathrm{f} 25 \mathrm{c} 50 \mathrm{n} 1$ & 210 & 25 & 50 & 1 & 15.68 & 79 & 0.896 & 58.9 \\
\hline 16 & $\mathrm{t} 250 \mathrm{f} 25 \mathrm{c} 100 \mathrm{n} 1$ & 250 & 25 & 100 & 1 & 16.72 & 85 & 0.955 & 61.3 \\
\hline 17 & t250f25c50n1 & 250 & 25 & 50 & 1 & 16.52 & 95 & 0.944 & 65.0 \\
\hline 18 & t250f38c100n1 & 250 & 37.5 & 100 & 1 & 16.30 & 104 & 0.931 & 68.3 \\
\hline 19 & t250f50c100n1 & 250 & 50 & 100 & 1 & 16.22 & 111 & 0.927 & 69.0 \\
\hline 20 & $\mathrm{t} 210 \mathrm{f} 25 \mathrm{c} 0 \mathrm{n} 1$ & 210 & 25 & 0 & 1 & 15.58 & 124 & 0.890 & 64.6 \\
\hline 21 & t250f25c0n1 & 250 & 25 & 0 & 1 & 16.54 & 138 & 0.945 & 71.1 \\
\hline
\end{tabular}

*) Number of samples on the plate 


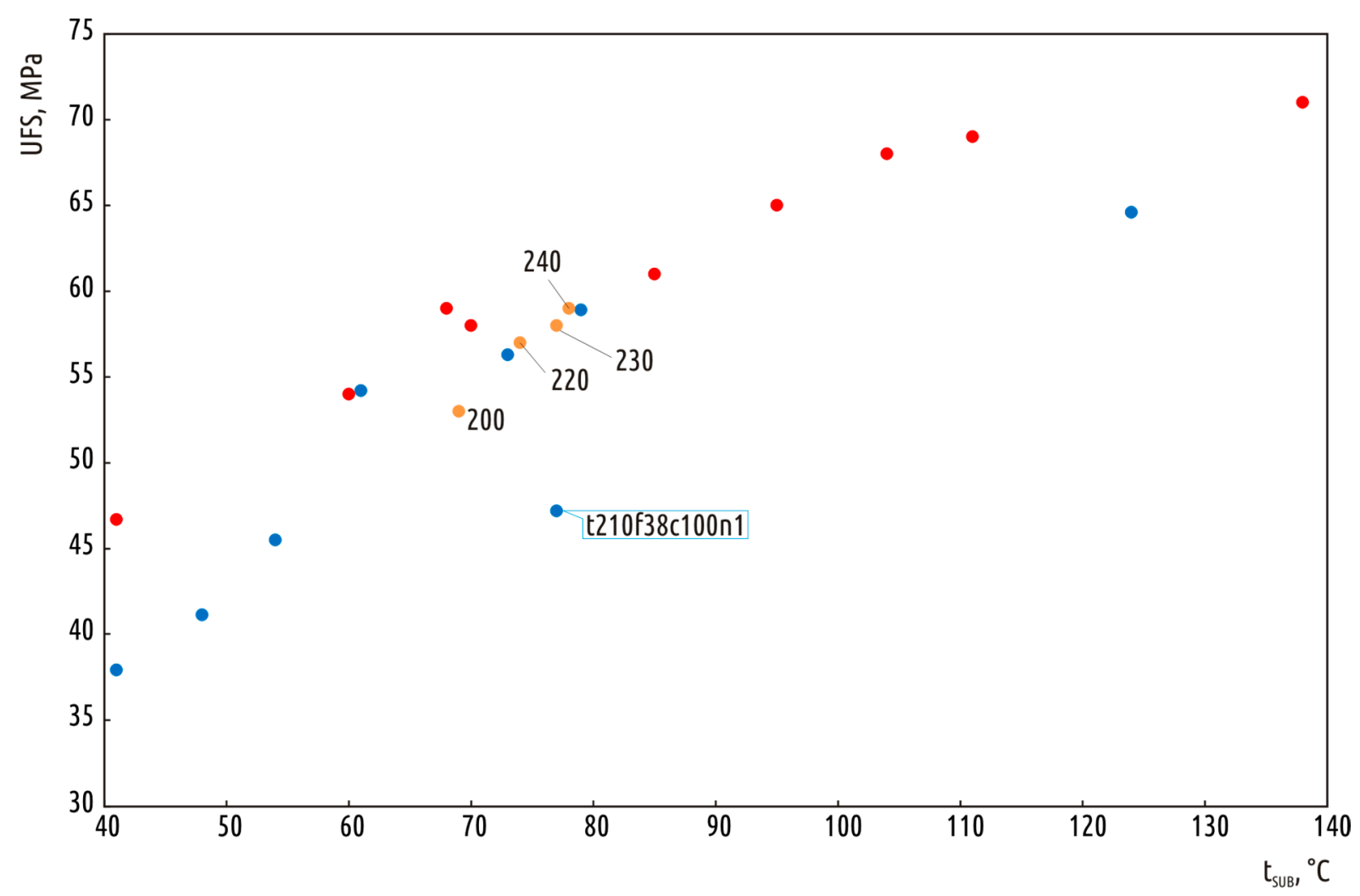

Figure 15. Scatter plot of UFS vs. tsuB

Blue marks are the points corresponding to the printing of samples at a temperature of $210^{\circ} \mathrm{C}$, the red ones at a temperature of $250^{\circ} \mathrm{C}$. Four orange dots are for $200,220,230$ and $240{ }^{\circ} \mathrm{C}$ from left to right. If lot\#13 is excluded as an outfitter, then it is possible to approximate all the dots with a single curve. Meanwhile better solution is to map all the parameters considered in the work onto a two-dimensional space (Figure 16).

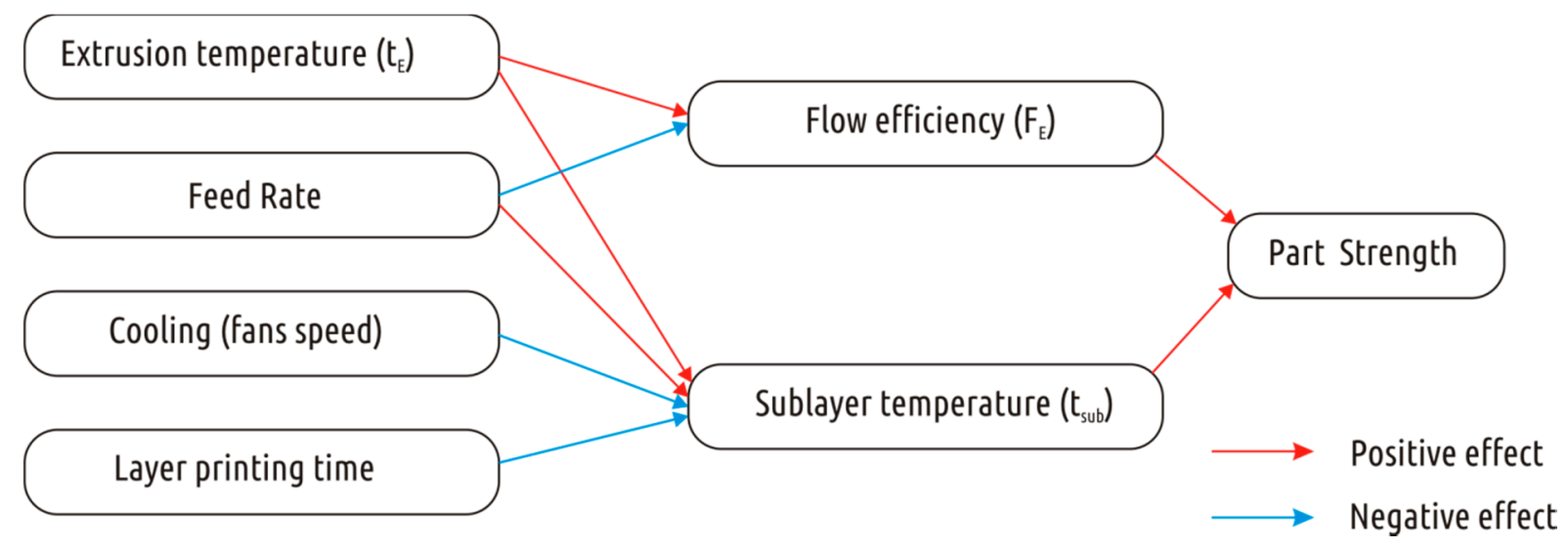

Figure 16. Factors influencing the part strength

The first and most obvious resulting factor becomes the $t_{S U B}$, which depends on all the parameters observed in the study.

The second resulting parameter can be named "flow efficiency" $\left(F_{E}\right)$. This parameter indicates the real amount of plastic extruded through the nozzle, compared to expected amount calculated by slicer. The easiest way to estimate this parameter is to find the ratio between the real mass of the sample and calculated one (filament density multiplied by 3D model volume; $17.5 \mathrm{~g}$ for the samples of current study). The $F_{E}$ is a reflection of extrusion resistance and it seems to be highly hardware dependent. For a single hardware setup (machine, nozzle) and material the $F_{E}$ depends on the $t_{E}$ and on the feed rate. The $F_{E}$ 
explains why the red dots $\left(t_{E}=250^{\circ} \mathrm{C}\right)$ are generally shifted in upper direction relational to the blue dots $\left(t_{E}=210^{\circ} \mathrm{C}\right)$ on the UFS vs. $t_{S U B}$ scatterplot (Figure 15$)$.

In this study, the limits of the range of observations of the $t_{S U B}$ are as close as possible to the physical limits. So, obviously, to get the $t_{\text {suB }}$ noticeably lower than $41^{\circ} \mathrm{C}$, one can only turn off the bed heating and (or) lower the room temperature. It is possible to obtain a significantly higher tsuB than observed when printing with fans turned off at a $t_{E}$ of $250^{\circ} \mathrm{C}$, for example, by increasing the printing speed. However, it is upper bound with PLA melting temperature; it will be difficult to obtain the part of the desired shape above it.

It also seems quite hard to get a value of $F_{E}$ lower than $\sim 0.85$ without getting visible underextrusion defects while keeping feed rate in reasonable limits and without trying to extrude PLA filament at $t_{E}$ below $210^{\circ} \mathrm{C}$. It is also challenging to get a value higher than $\sim 0.96$ without going beyond part tolerance (it is possible to increase the flow both in slicer and manually in printer menu, but that will cause overextrusion at external boundaries and part going beyond expected dimensions).

UFS dependency on two resulting factors can be described by following regression model:

$$
U F S=a+b \times \ln \left(t_{\text {sub }}\right)+c \times F_{E},
$$

with following coefficients found by least squares optimization (Table 2) and the $\mathrm{R}^{2}$ equal to 0.956 .

Table 2. Fitting parameters for regression model

\begin{tabular}{lllllll}
\hline Coeff. & Estimate & $\begin{array}{l}\text { Standard } \\
\text { error }\end{array}$ & t-value & p-level & $\begin{array}{l}\text { Lo. Conf } \\
\text { Limit }\end{array}$ & $\begin{array}{l}\text { Up. Conf } \\
\text { Limit }\end{array}$ \\
\hline $\mathrm{a}$ & -153.912 & 15.30031 & -10.0594 & 0.000000 & -186.057 & -121.767 \\
$\mathrm{~b}$ & 23.945 & 1.37579 & 17.4043 & 0.000000 & 21.054 & 26.835 \\
$\mathrm{C}$ & 116.580 & 16.10235 & 7.2399 & 0.000001 & 82.750 & 150.409 \\
\hline
\end{tabular}

The model is plotted on the figure 16 and the quality of approximation can be evaluated by plot on Figure 18. 


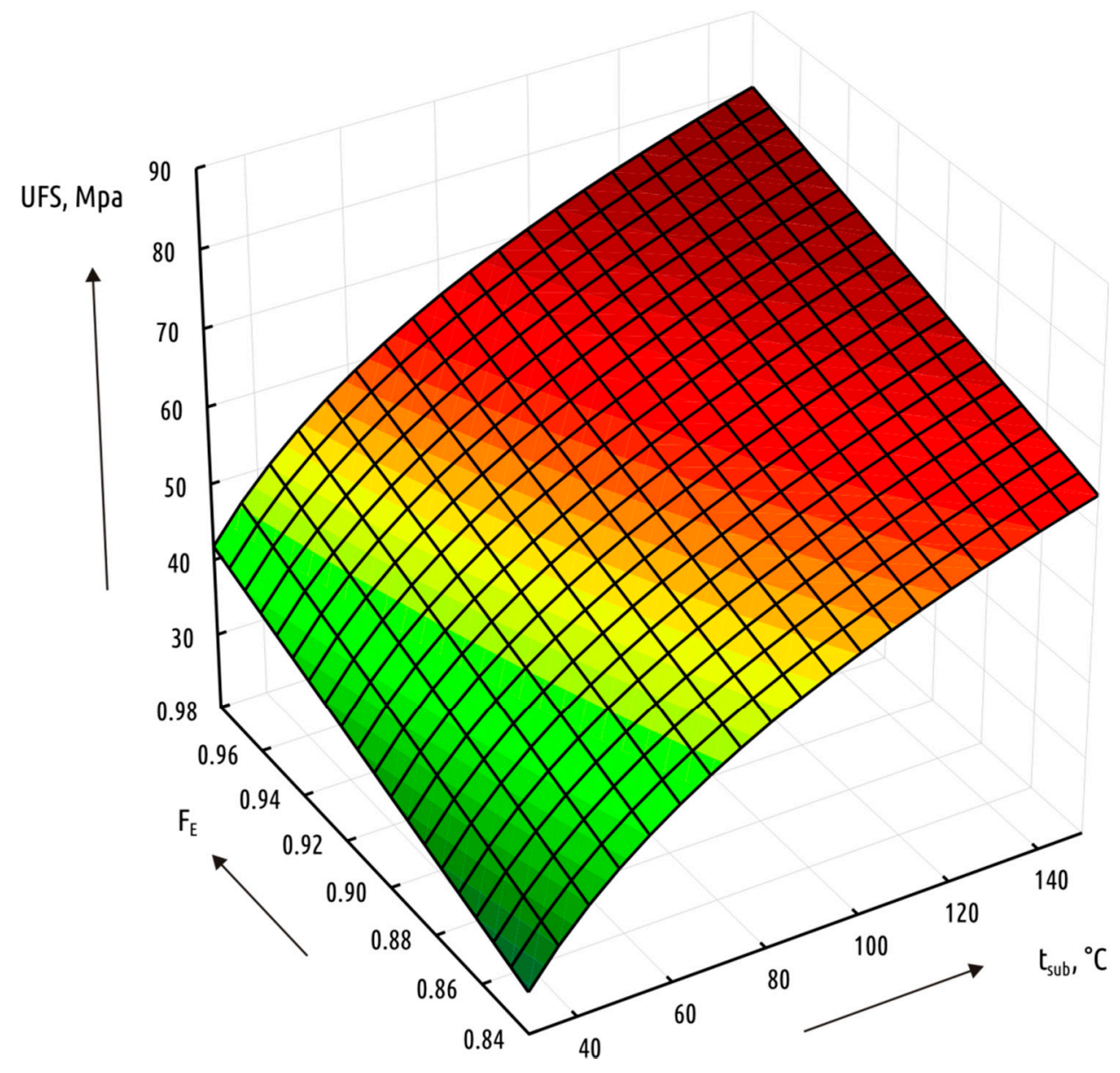

Figure 17. Response surface for regression model $U F L=f\left(t_{S U B}, F_{E}\right)$

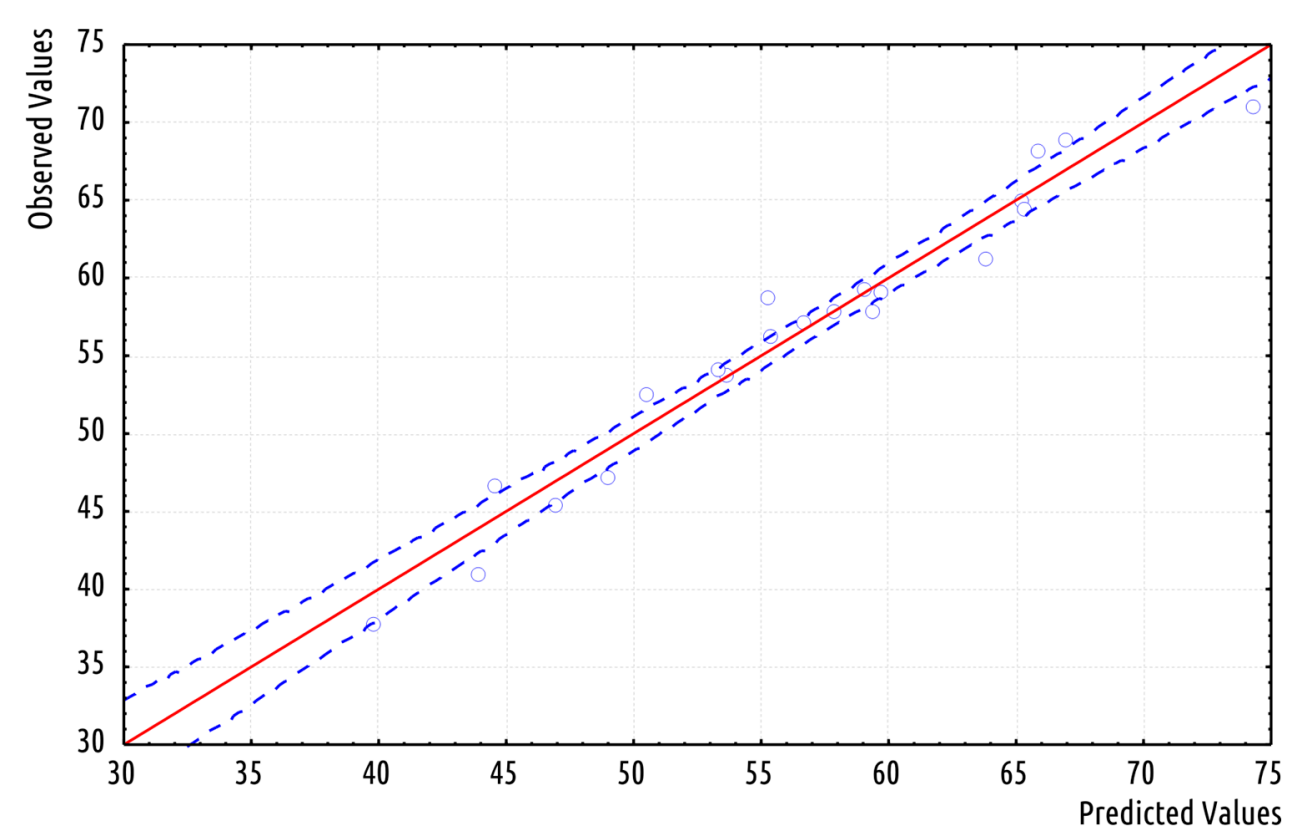

Figure 18. Observed versus predicted values (0.95 confidence interval)

In general, the apparent and significant effect of $t_{S U B}$ on the part strength and also the inability to directly control this parameter raises the question of whether it is advisable to use printers with a controlled temperature chamber or printers with local heating [7, 22 - 24] sublayer for printing with PLA. 


\subsection{Structure morphology}

The temperature conditions of FDM (FFF) process do not only affect measurable bonding strength, but also printed object structure. The boundary formation between individual threads is influenced by technological parameters investigated in this paper, which, as it was mentioned above, can be reduced to two factors: the $F_{E}$ and the $t_{\text {SUB. }}$. The first affects the volume of voids between threads (see figure 5), and the second affects the shape of the voids (see Figure 9).

The most durable sample considered (printed with fans turned off and the $t_{E}$ of $250^{\circ} \mathrm{C}$ ) contains voids with sections being almost ideal circles (Figure 19).

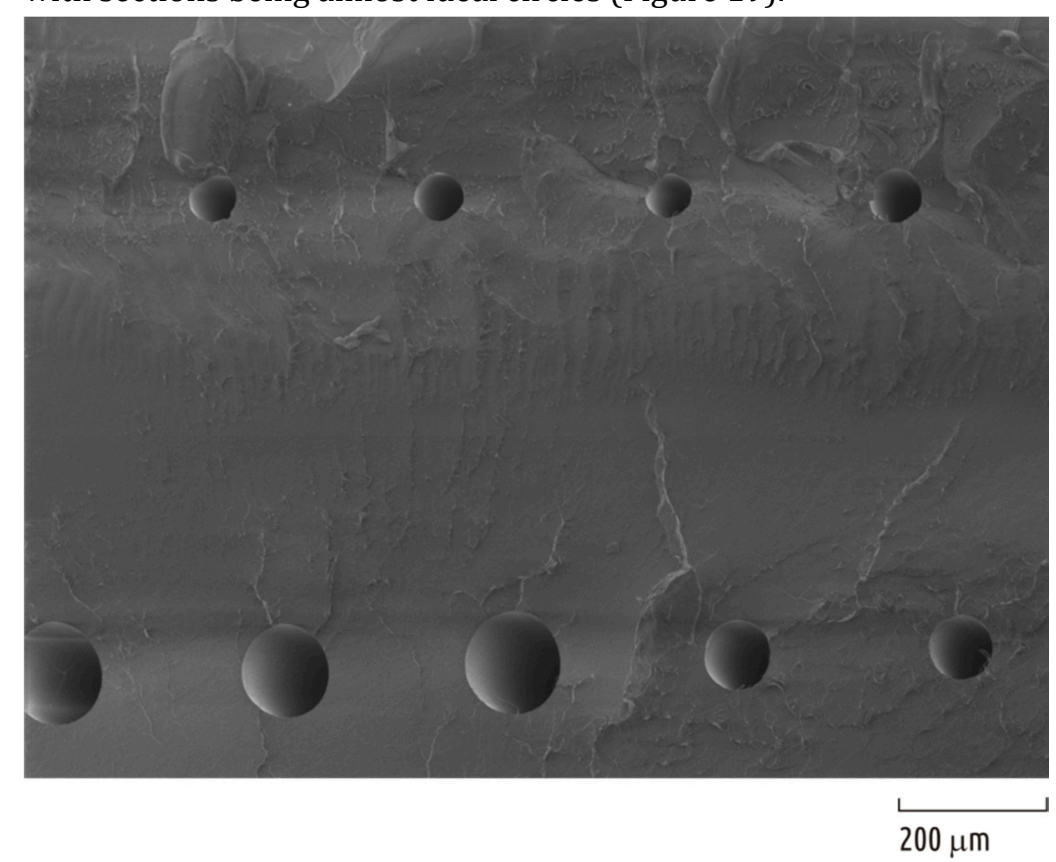

Figure 19. Mesostructure of sample from lot \#21

The most suitable explanation for this phenomenon is that boundaries formation was ruled by surface tension forces in the liquid phase. None of the cases examined with the thermal imager exhibited the $t_{S U B}$ higher than the melting point of PLA. However, limited resolution of the device does not allow to measure the temperature of individual threads. The sublayer thread can be melted when contacting with a hot thread squeezed out of the nozzle. The depth of this fusion obviously depends on both threads temperature $\left(t_{E}\right.$ and $\left.t_{S U B}\right)$. Melting depth and the period when neighboring threads material remains in the liquid phase determines the shape of the voids cross-section - from subtle roundings at the angles to complete conversion into a circle.

Let us consider in more detail the process of voids formation between the threads forming the product on the example of sample from lot “\#18” (Figure 20). 

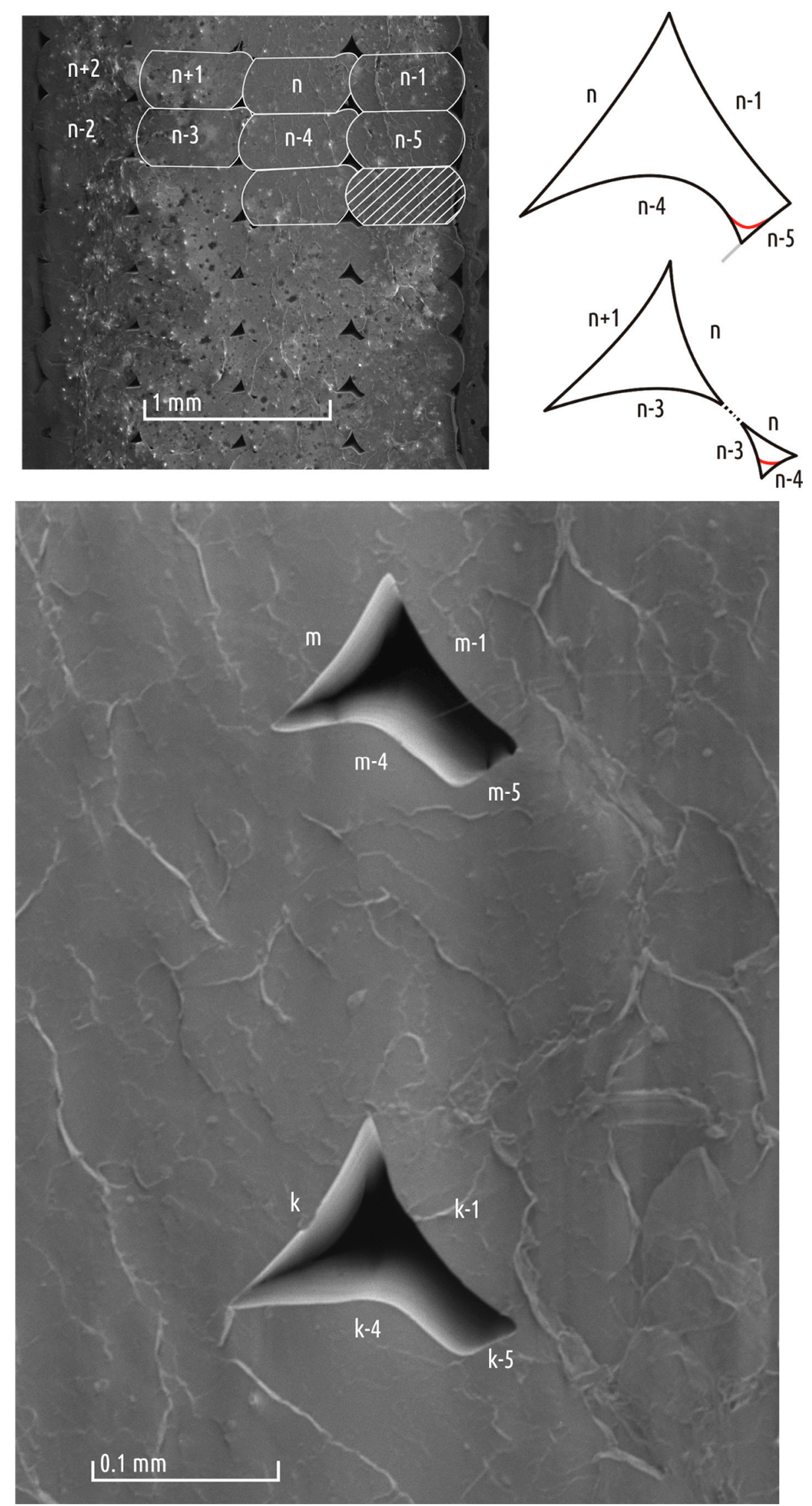

Figure 20. Structure formation (sample from lot\#18) 
The upper part of the figure shows a fragment obtained in the longitudinal section of the sample magnified at 100x. The sections of individual plastic threads and the printing sequence can be clearly read. The shell is printed inside out, that is, first the thread with the smallest perimeter is laid, and then the next threads forming the layer are laid around it. The letter " $n$ " denotes the section of a certain thread, respectively, " $n-1$ " and " $n+1$ " are its immediate neighbors, laid just before and right after the thread in question. In the current case, each layer consists of four perimeters (the wall thickness of the sample is $2.4 \mathrm{~mm}$, the nozzle diameter is $0.6 \mathrm{~mm}$ ), thus thread $n$ is laid over the $n-4$ and serves as a substrate for the $n+4$ filament. The cross-section of the filaments of the first (inner) perimeter $(n-1, n-5)$ is characterized by a symmetrical barrel-like structure: this thread is limited only from the bottom (the previous layer) and from the top (the nozzle); the liquid plastic flows freely in both side directions. When forming subsequent threads, for example, $n$, restrictions appear not only from above and from below, but also from the side of the previous $(n-1)$ thread. The plastic flows freely towards $n+1$ and a vertically symmetric convex wall is formed here, but in the direction of $n-1$ thread, the liquid plastic encounters an the previous thread $(n-1)$ being an obstacle and bends around it. Accordingly, a somewhat larger amount of plastic flows towards the $n+1$ side than towards the $n-1$ side. At the bottom, thread $n$ contacts a relatively cold substrate $(n-4)$, whereas on the top it is pressed with a hot nozzle and hot liquid plastic still in the nozzle. Accordingly, when the liquid plastic bends around previous thread, more material flows upwards rather than downwards, causing a characteristic step (the upper part of the boundary $n-n-1$ or $n-4-n-5$ ). The step occurs when the second and subsequent threads are deposited, and, with each subsequent thread, this step increases. Therefore, when depositing the thread $n$ the plastic flowing towards $n+1$ touches the step from $n-3$ to $n-4$ and the void is divided into two parts. Thus, the geometry of the void is formed to the right and left of the thread $n$ (Figure 20, top, right). Plastic of the previous threads should start melting from contact with the liquid plastic at the boundary with the highest temperature, and this boundary is the contact point between the step and the preceding thread $n-4-n-5$ and $n-3-n-4$, and it is possible to observe the formation of the first fillets, as can be seen in the photographs obtained at $1000 \times$ zoom (Figure 20, bottom).

A similar picture can be observed at the sample from lot \#19 (Figure 21). The difference between samples from lots \#18 and \#19 is in increased printing speed (37.5 and $50 \mathrm{~mm} / \mathrm{s}$, respectively), which caused, on one side, some decrease of flow efficiency and increase in registered $t_{S U B}$ on the other. The flow efficiency drop resulted in certain increase in the voids area and, more significantly, in the fact that the voids between the second and third, as well as between the third and fourth perimeters were not divided into two channels, as in the sample from lot \#18. The rise of $t_{\text {SUB }}$ led to the fact that fillets appeared not only in $n-4-n-5$ nodes, but also in $n-5-n-1$ and $n-n-1$ (Figure 21, below). 

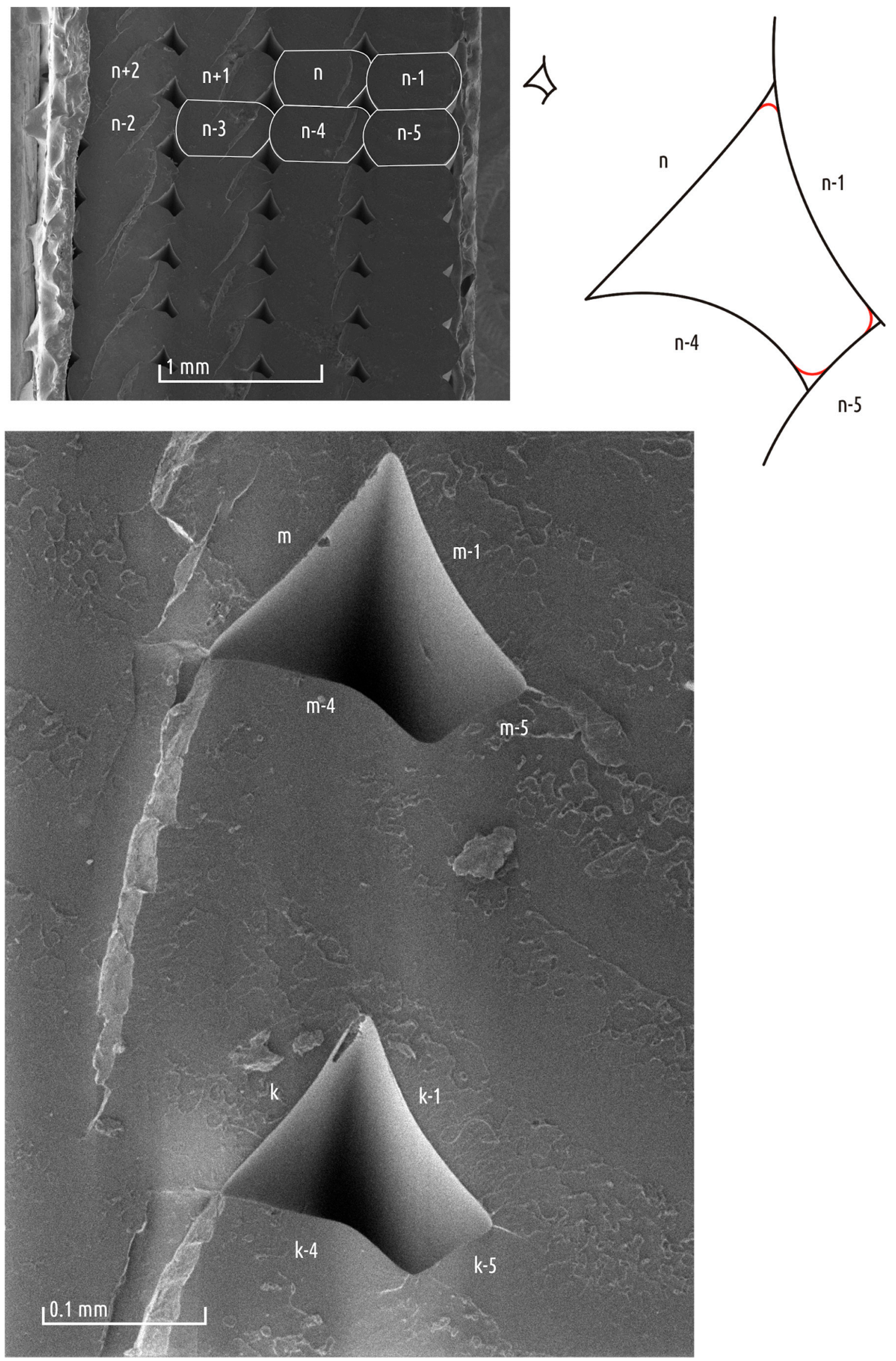

Figure 21. Formation of the structure (sample from lot \#19) 
Further increase of $t$ suB (sample from lot \#20) caused fillets to appear already at the $n-n-1$ junction (the lower part of the boundary between the next and previous thread), and the two nodes $n-4-n-5$ and $n$ 4- $n$-1 merge (Figure 22).
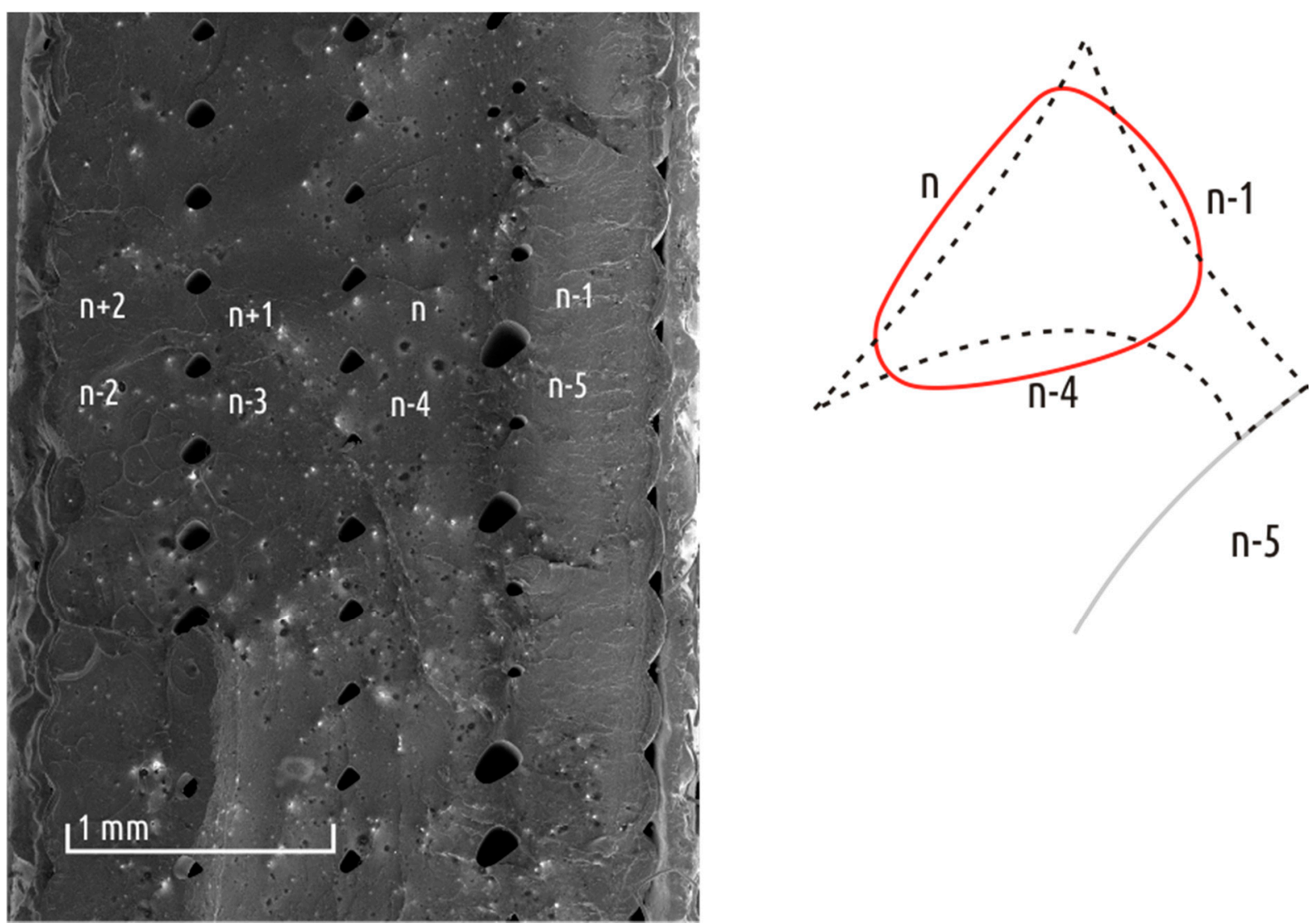

Figure 22. Formation of the structure (sample from lot \#20)

Finally, as the $t_{S U B}$ rises further to $138^{\circ} \mathrm{C}$ (sample from lot \#21), the shape of the cross-section approaches the ideal circle, indicating that after applying the thread $n$ the entire system $n-n-1-n-4-n-5$ is in liquid state for sufficient time to complete smoothing of the boundaries (see Figure 19).

Generalized influence of flow efficiency and the $t$ sUB can be graphically expressed by the schematic on Figure 23. 

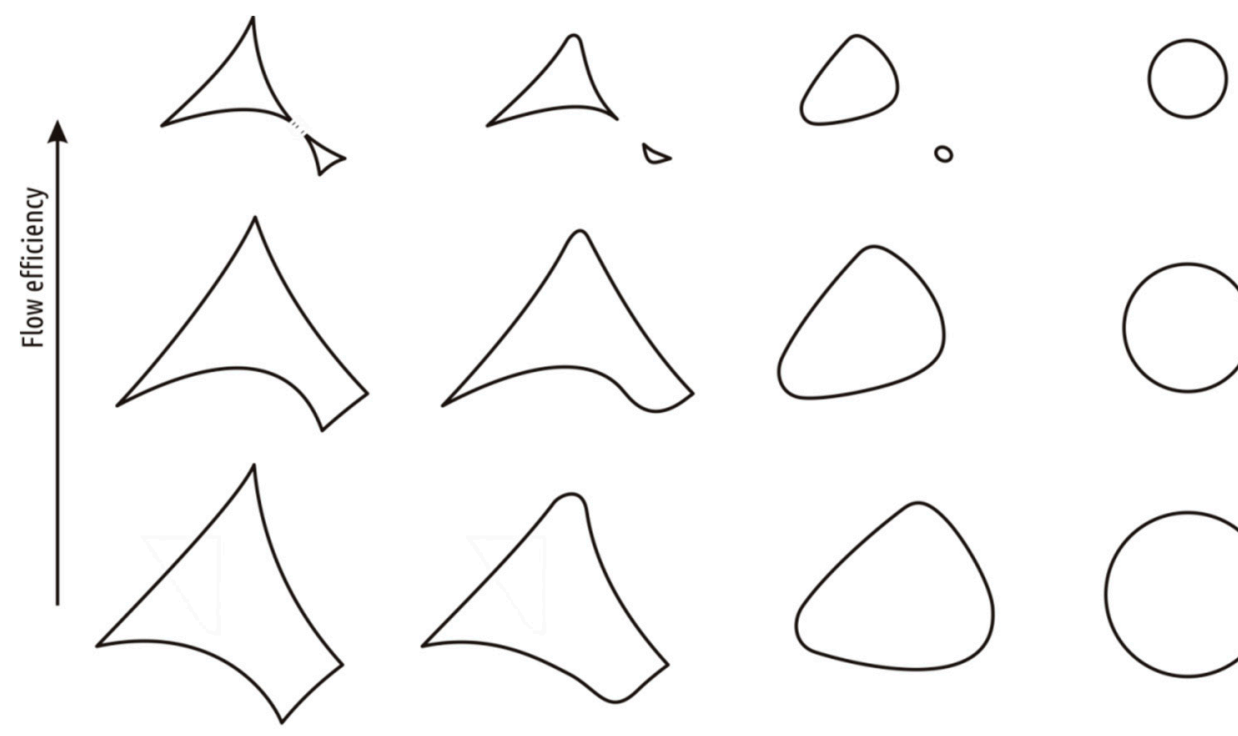

○

O

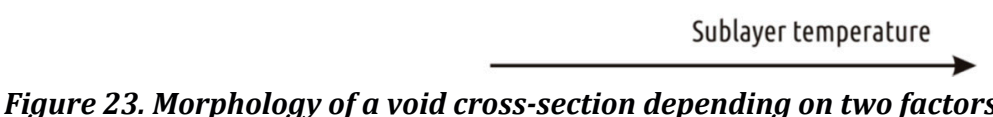

Figure 23. Morphology of a void cross-section depending on two factors

There is an interesting fact: the most drastic metamorphoses in inter-thread boundaries structure visible with SEM occurs when $t_{S U B}$ gets close to the material melting point, but these changes are not followed by major changes in the part strength. The most steep part of UFS w.r.t. tsUB curve shows a qualitative change in part strength earlier, when increasing tsuB from minimum to approximately $75 \ldots 80^{\circ} \mathrm{C}$ leads to stronger cohesion without affecting visible voids structure.

\subsection{Comparing with reference}

Comparing test results with reference samples printed with maximum dimension oriented along Y axis (and, thus, with load applied along threads) is of great practical interest.

Comparison of the bending curves of the typical samples with the reference one (Figure 24) allows us to draw a number of conclusions. As typical, representatives of following lots could be considered. Lot \#21 provides "best" sample (A), lot \#10 provides an "average" sample (B), and, finally, lot \#1 is the worst observed case. 


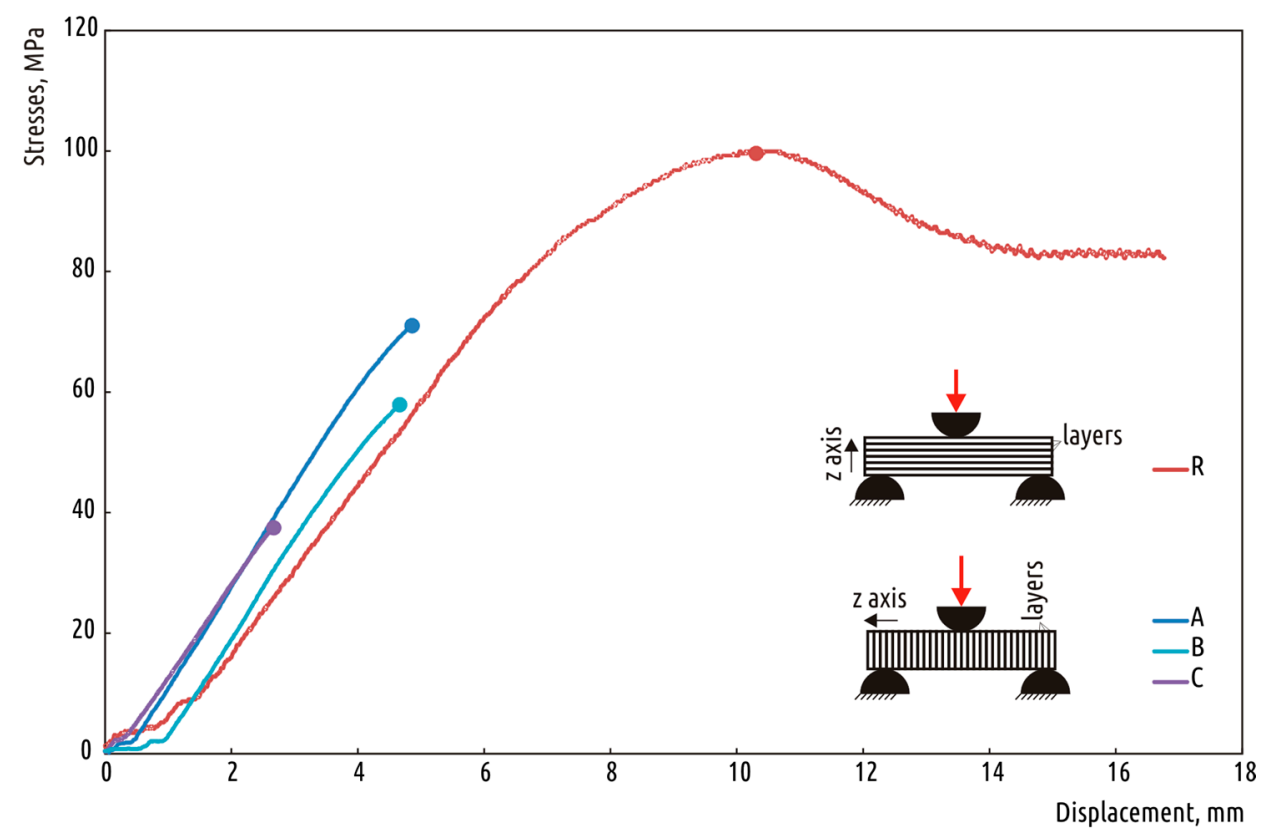

Figure 24. Test curves for samples loaded along (R) and across $(A, B$ and $C)$ the layers

Reference samples were fractured with a significant plastic deformation (Figure 24, curve R), while in the samples from the main set the plastic deformations are negligible (Figure 24, curves A, B and C). As it can be seen from the curves, optimizing parameters that affect the temperature conditions during the formation of interlayer bonds allows to significantly reduce the gap in strength between testing along and across the layers. However, a complete solution of the anisotropy problem of FDM (FFF) products is not reached, since in addition to quantitative differences in strength along and across the layers, qualitative differences remain (the presence and absence of a plastic zone). Comparable results have been obtained in [24].

\subsection{Comparing with previous study}

Another useful validation is comparison with the results of a previous study [17] in which PLA samples of identical geometry obtained with a standard $t_{E}$ of $\left.210^{\circ} \mathrm{C}\right)$ and fixed print speed $(25 \mathrm{~mm} / \mathrm{sec})$ were tested using nozzles of different diameters, with varied layer thickness. For a $0.6 \mathrm{~mm}$ nozzle, data for layer thickness values in the range from 0.1 to $0.6 \mathrm{~mm}$ were obtained, while in the whole range decrease in the sample strength was registered along with layer thickness increase. Accordingly, the average maximum (68 MPa) of the strength of the nozzle was 0.6 was recorded for the layer $0.1 \mathrm{~mm}$, which is practically the same as the maximum of the current study (71.1 MPa). Decreasing layer height results in $\mathrm{F}_{\mathrm{E}}$ increase, however, this increase at transition from "nozzle $0.6 \mathrm{~mm}$ - layer 0.3 " to "nozzle $0.6 \mathrm{~mm}-0.1 \mathrm{~mm}$ layer" configuration is insignificant (0.913-0.920) and cannot explain such a great increase in strength. Moreover, the second of the resultant parameters of the present study, $t_{S U B}$, decreases with thinner layers being printed. Thus, the factors studied in this paper do not completely determine the conditions for the formation of the bond between the layers and, accordingly, the strength of the product. Another important factor determining the cohesion strength of the layers remains the N/L ratio, considered in [17].

\section{Case studies}

The following case studies were implemented to demonstrate practical usefulness of the results obtained. For three tasks, parts were designed to be printed using desktop 3D printer, two lots of test parts were manufactured for each case. The first lot $(\mathrm{A})$ was made with $t_{E}$ of $210^{\circ} \mathrm{C}$ and maximum cooling intensity. The second lot (B) was printed with $t_{E}$ of $250^{\circ} \mathrm{C}$ and with fans switched off. All other technological parameters were kept intact: $25 \mathrm{~mm} / \mathrm{s}$ linear speed, bed temperature $60^{\circ} \mathrm{C}$, layer thickness equal to 0.3 
$\mathrm{mm}$. The parts were made with the same 3D printer and using the same nozzle $(0.6 \mathrm{~mm})$, which carried out the primary research samples fabrication. Wall thickness was set so that the whole part consisted of a shell only. All parts were made from PLA.
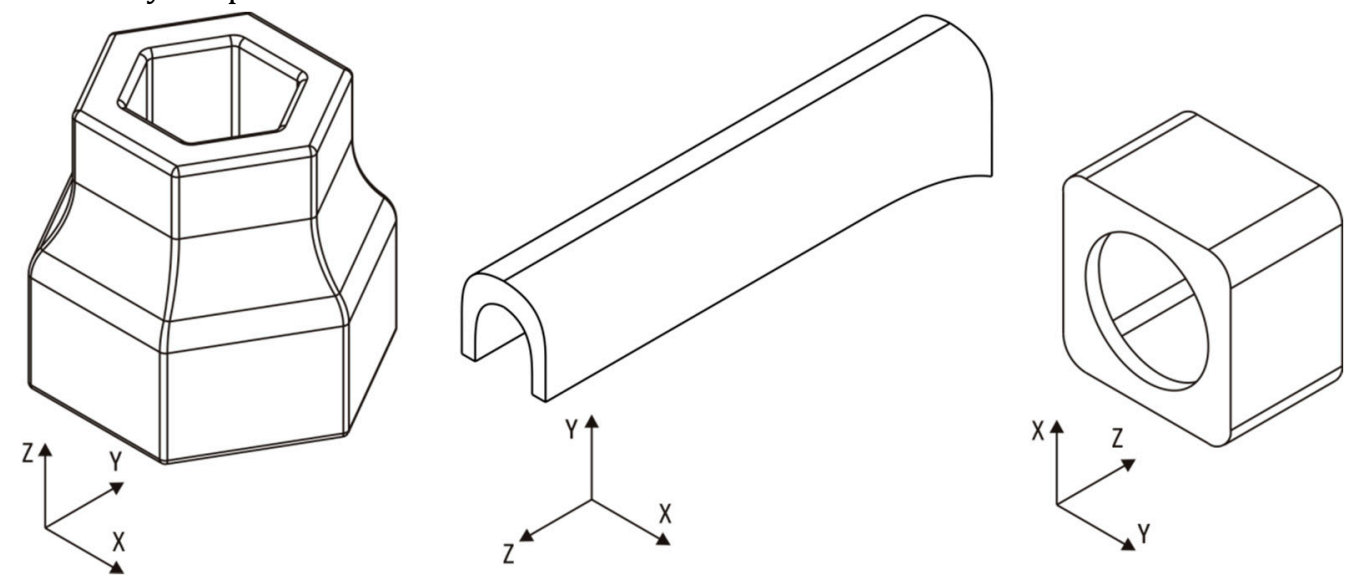

Figure 25. Case study parts and their orientation during fabrication

\section{Case 1. Box spanner adapter}

This part (Figure 25, left) serves as an adapter, allowing the use of standard $32 \mathrm{~mm}$ head for tightening 30 mm nuts. Products were tested using a beam-type torque wrench while tightening an M20 nut. During the test, the destructing torque was recorded when the adapter cracked or deformed permanently. The measuring accuracy using the torque wrench of this type is not high (unit value is $10 \mathrm{~N} \cdot \mathrm{m}$ ), but that is sufficient for comparing two significantly different technological modes of printing.

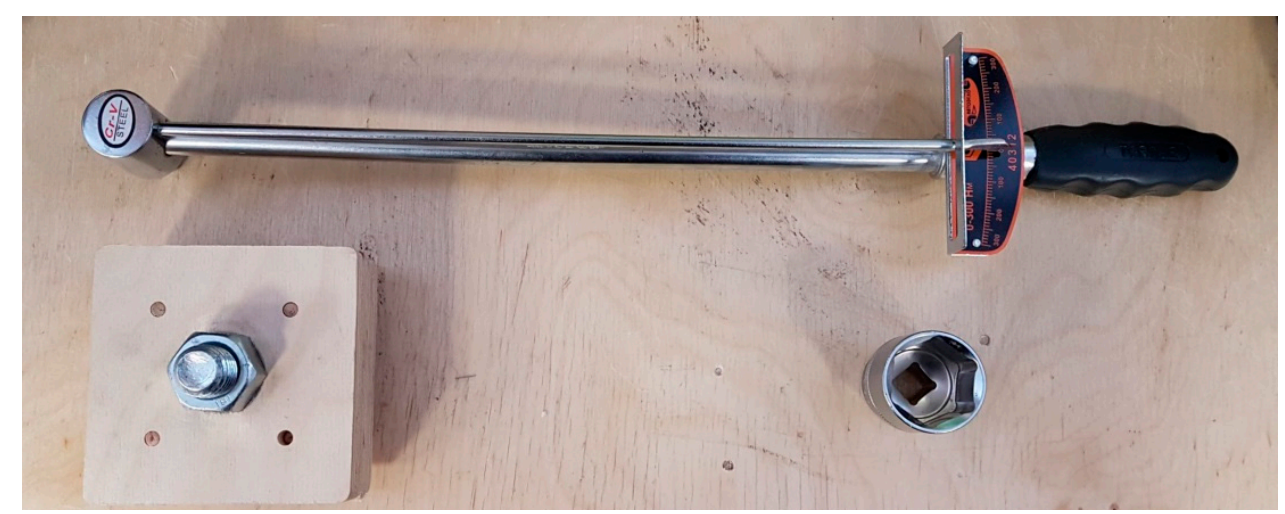

Figure 26. Fixtures for testing the adapter strength

Lot A samples destruction happened at the moment of $40 \ldots 70 \mathrm{~N} \cdot \mathrm{m}$ with a mean of $48 \mathrm{~N} \cdot \mathrm{m}$, while the products from lot B exhibited $100 \ldots 120 \mathrm{~N} \cdot \mathrm{m}$ with an average of $110 \mathrm{~N} \cdot \mathrm{m}$. Destruction nature also differs (figure): in the case of lot A, the nut cap is deformed, while in lot B samples cracks appear in the maximally loaded areas. 

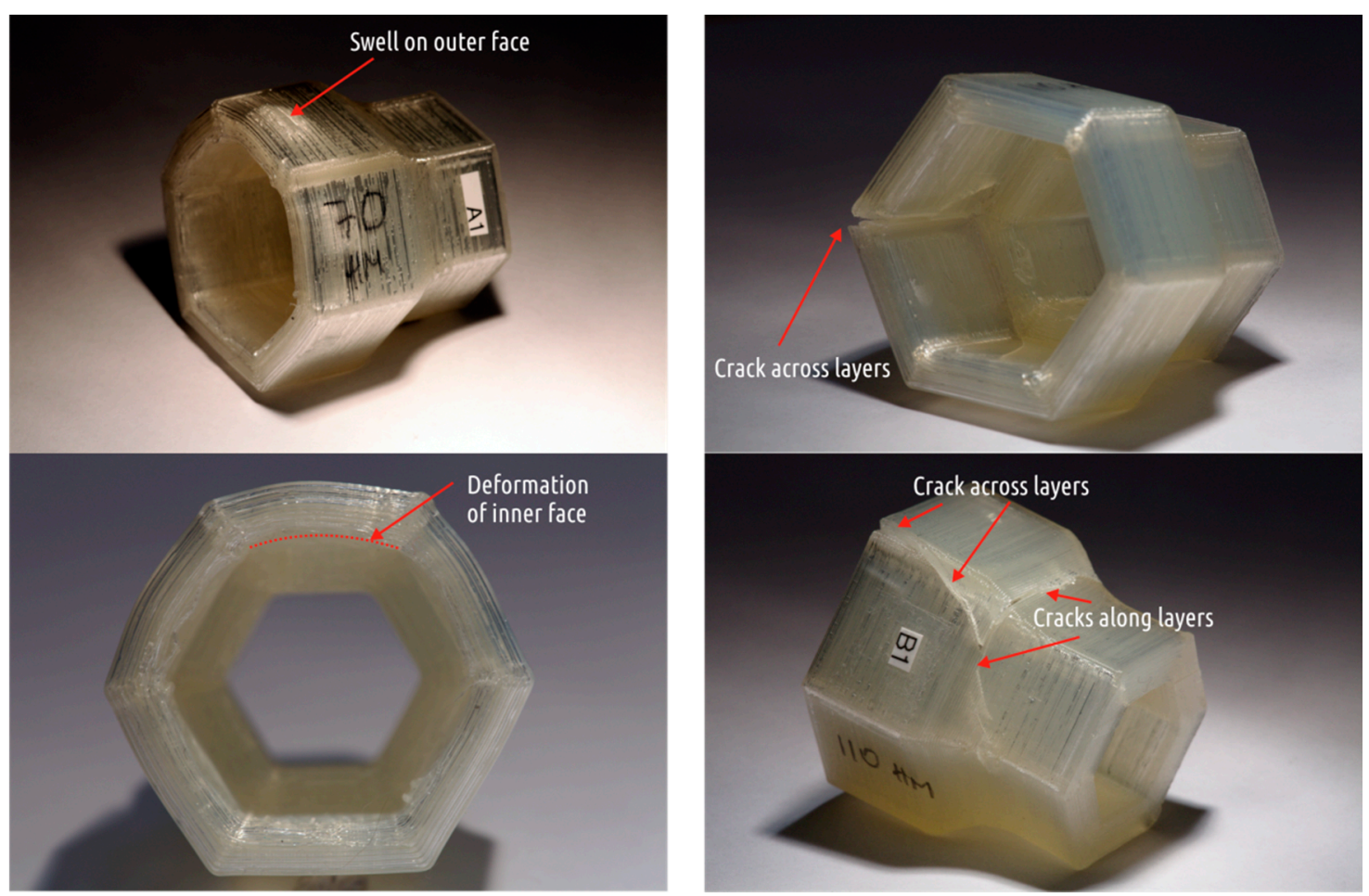

Figure 27. Destruction of a sample from lot A (left) and B (right)

\section{Case 2. Spike heel enclosure}

This product (Figure 25, middle) is designed to protect expensive women's shoes heels in the aggressive environment, such as public transport or cobblestone.

The nature of the intended use of the product implies periodic shock loads, which defined the test method for that case. An impact tester POE 2000 Instron was used for testing and comparing strength of the products from two lots.

The data in load w.r.t time curves were recorded; typical representatives from both lots are presented in the Figure 28.

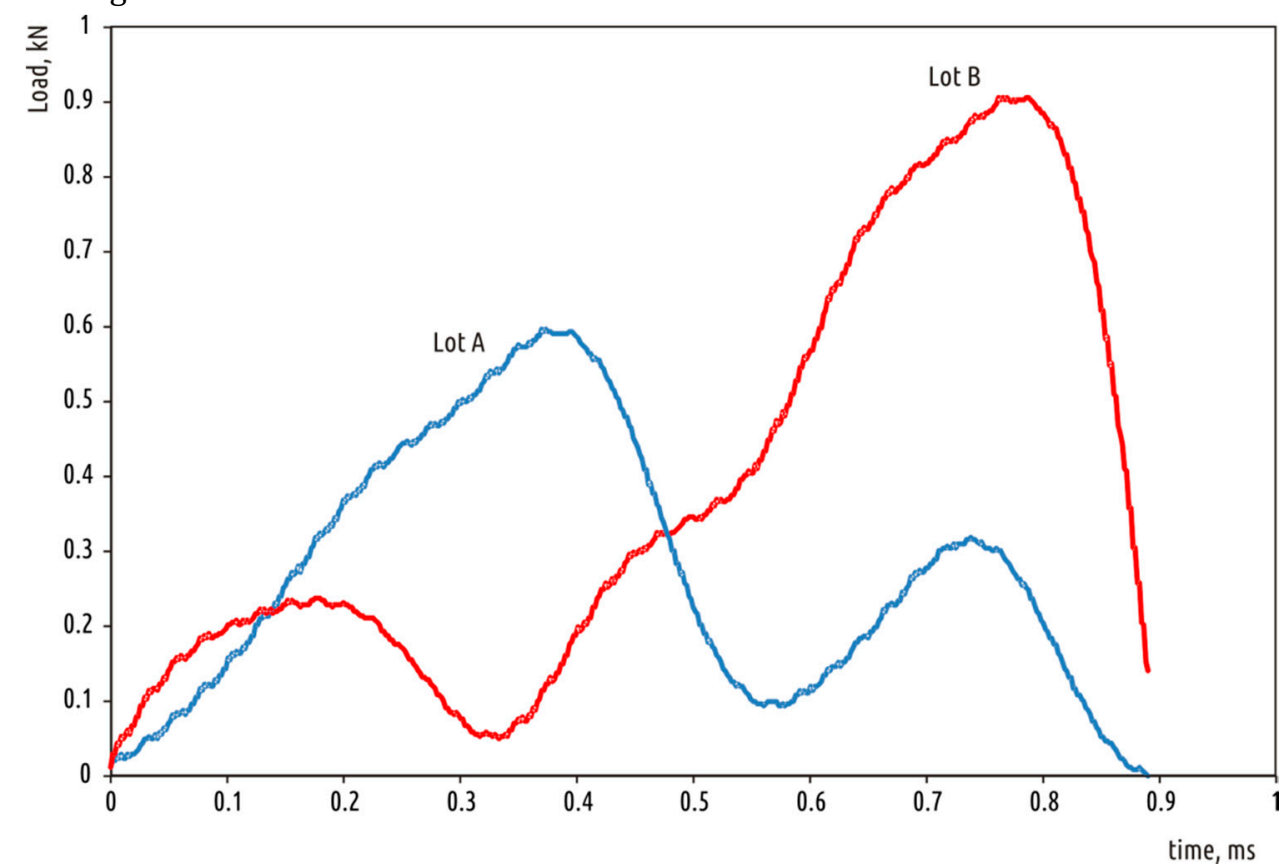

\section{Figure 28. Impact testing (Case 2)}

The testing product has a U-shape cross-section, thus the impact testing curves includes two pikes. 
The maximum loads observed are $590 \ldots 684 \mathrm{~N}$ for lot $\mathrm{A}$ and $850 \ldots 953 \mathrm{~N}$ for lot B samples.

\section{Case 3. Device housing}

Housing (Figure 25, right) was printed in a shape of a parallelepiped with square base and dimensions of $30 \times 30 \times 20 \mathrm{~mm}$. One of square faces features a circular hole in the center, another one is fully open. Samples were tested for maximum compression force using the same universal test machine that was used for testing of samples in the main part of the study. Compression is carried out between two flat parallel plates, while the object was placed on the bottom of the plate in the same orientation in which it was printed (layers were parallel plates).

Deformation nature does not differ significantly in these two cases (Figure 29): the zone of elastic deformation is followed by a short zone of uniform plastic deformation, the end of which corresponds to the peak load value. Further reduction of effort occurs due to loss of the product buckling.

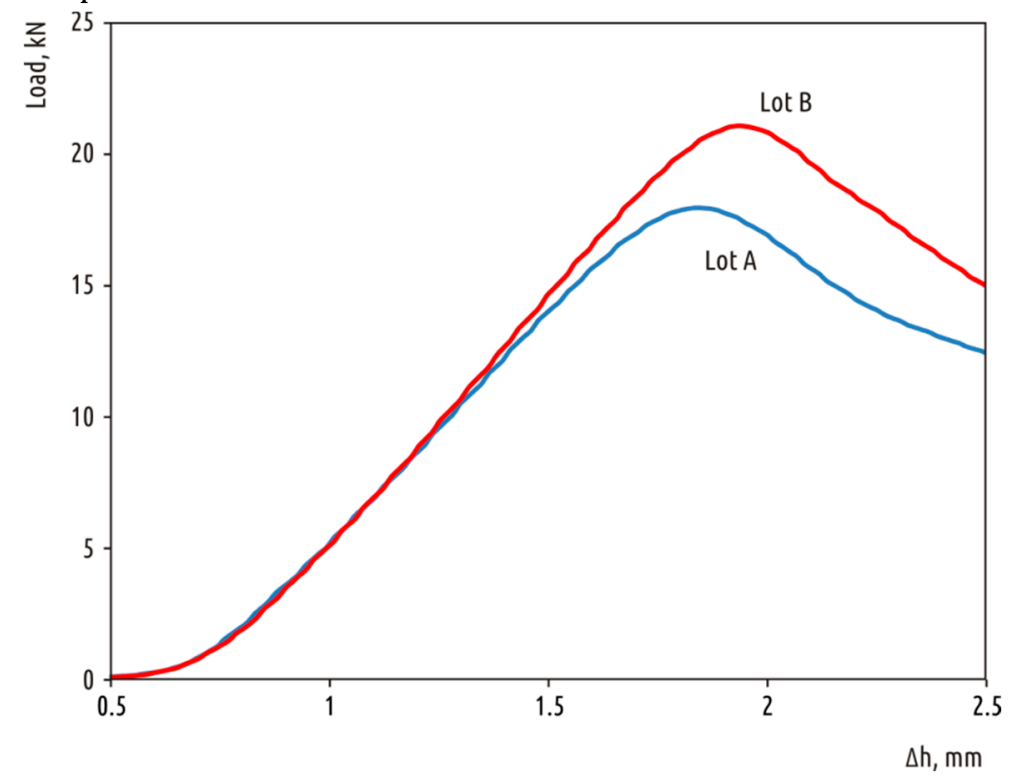

Figure 29. Compression testing (Case 3)

The average maximum force for lot A amounted to $17.86 \mathrm{kN}$, and $21.07 \mathrm{kN}$ for lot $\mathrm{B}$.

For all the three cases parts fabricated with elevated $t_{E}$ and fans switched off (lots B) demonstrated noticeable better performance than parts fabricated with default conditions. 


\section{Conclusions}

1. Changing temperature conditions of the layer-by-layer polymer deposition process has a significant effect on the cohesion strength of the layers and, accordingly, on the strength of the part. It is shown that the optimization of the FDM (FFF) process parameters responsible for temperature conditions makes it possible to approximate the strength of the interlayer cohesion to the bulk material strength.

2. Increasing extrusion temperature in the range investigated positively affects the part strength. Out of all process parameters studied, the extrusion temperature is the only factor whose effect on the strength depends to a small extent on the size and shape of the product (single layer printing time). The increase in part strength is explained both by activation of temperature-dependent processes of bond formation between the layers, and by an increase in the volume of the extruded plastic and, correspondingly, by a decrease in cavities and voids volume at the interface of the adjacent layers.

3. Cooling conditions (the intensity of fans blowing) also have significant effect on the part strength. The effect of this process parameter strongly depends on part dimensions, more precisely, on the time of printing of a separate layer: if it is large enough, it cools down naturally.

4. Printing speed has an ambiguous effect on the part strength. On one hand, with increasing speed, the efficiency of extrusion decreases (the actual amount of material squeezed through the nozzle per unit of time); on the other hand, as the printing speed increases, the time interval between printing the layers is reduced.

5. Increase in the time interval between the printing of two adjacent layers adversely affects the part strength.

6. The influence of all parameters considered on the part strength can be expressed through two generalizing factors. The first factor determining the ratio of the amount of really extruded plastic to the calculated one is called flow efficiency $\left(F_{E}\right)$. Its value is determined by the joint effect of extrusion temperature and printing speed. The second generalizing factor is the temperature of the previous layer (sublayer), depending with different coefficients on all four parameters considered in the work.

7. A regression model is proposed that adequately $\left(\mathrm{R}^{2}=0.956\right)$ describes the effect of $F_{E}$ and $t_{S U B}$ on the printed part strength.

8. These two factors $\left(F_{E}\right.$ and $\left.t_{S U B}\right)$ determine the formation of the part mesostructure (the geometry of the boundaries between individual threads).

\section{Acknowledgments}

The work was carried out with financial support from the Ministry of Education and Science of the Russian Federation in the framework of increase Competitiveness Program of NUST "MISIS", implemented by a governmental decree dated 16th of March 2013, No. 211.

The authors express their heartfelt thanks to their colleagues for their support.

\section{Author Contributions}

Vladimir E. Kuznetsov and Alexey N. Solonin conceived and designed the experiments; Azamat G. Tavitov performed the experiments; Vladimir E. Kuznetsov and Oleg D. Urzhumtsev analyzed the data; Alexey N. Solonin contributed analysis tools; Anna H. Vakulik performed the case study; Vladimir E. Kuznetsov wrote the paper.

\section{Conflicts of Interest}

The authors declare no conflict of interest. 


\section{References}

1. John Ryan C. Dizon, Alejandro H. Espera, Qiyi Chen, Rigoberto C. Advincula, Mechanical characterization of 3D-printed polymers,Additive Manufacturing, Volume 20, 2018,Pages 44-67, https://doi.org/10.1016/j.addma.2017.12.002.

2. Crump S., Fast, Precise, Safe Prototype with FDM, ASME PED, vol. 50 (1991), pp. 53-60

3. Crump S., The extrusion process of fused deposition modeling, - Proc. of 3rd Intl. Conf. on Rapid Prototyping, 1992

4. Jones R., Haufe P., Sells E., Iravani P., Olliver V., Palmer C., Bowyer A., RepRap - the replicating rapid prototyper. Robotica, 2011, Vol. 29, Issue 1, pp. 177-191 doi:10.1017/S026357471000069X;

5. Tymrak, B. M., Kreiger, M., \& Pearce, J. M. (2014). Mechanical properties of components fabricated with open-source 3-D printers under realistic environmental conditions. Materials and Design, 58, 242-246. https://doi.org/10.1016/j.matdes.2014.02.038

6. Costa, S. F., Duarte, F. M., \& Covas, J. A. (2017). Estimation of filament temperature and adhesion development in fused deposition techniques. Journal of Materials Processing Technology, 245, 167-179.

7. Go, J., Schiffres, S. N., Stevens, A. G., \& Hart, A. J. (2017). Rate limits of additive manufacturing by fused filament fabrication and guidelines for high-throughput system design. Additive Manufacturing, 16, 1-11. https://doi.org/10.1016/j.addma.2017.03.007

8. Ćwikła, G., Grabowik, C., Kalinowski, K., Paprocka, I., \& Ociepka, P. (2017). The influence of printing parameters on selected mechanical properties of FDM/FFF 3D-printed parts. IOP Conference Series: Materials Science and Engineering, 227(1). https://doi.org/10.1088/1757899X/227/1/012033

9. T. Letcher, M. Waytashek Material property testing of 3D-printed specimen in PLA on an entrylevel 3D printer. Proceedings of the ASME 2014 International Mechanical Engineering Congress \& Exposition (IMECE2014), Montreal (2014)

10. Ahn, S. -., Montero, M., Odell, D., Roundy, S., \& Wright, P. K. (2002). Anisotropic material properties of fused deposition modeling ABS. Rapid Prototyping Journal, 8(4), 248-257. 10.1108/13552540210441166

11. Melenka, G. W., Cheung, B. K. O., Schofield, J. S., Dawson, M. R., \& Carey, J. P. (2016). Evaluation and prediction of the tensile properties of continuous fiber-reinforced 3D printed structures. Composite Structures, 153, 866-875. 10.1016/j.compstruct.2016.07.018

12. J. Cantrell, S. Rohde, D. Damiani, R. Gurnani, L. DiSandro, J. Anton, A. Young, A. Jerez, D. Steinbach, C. Kroese, P. Ifju Experimental characterization of the mechanical properties of 3D printed ABS and polycarbonate parts S. Yoshida, L. Lamberti, C. Sciammarella (Eds.), Advancement of Optical Methods in Experimental Mechanics - Conference Proceedings of the Society for Experimental Mechanics Series, vol. 3, Springer, Cham (2017)

13. Costa, S. F., Duarte, F. M., \& Covas, J. A. (2017). Estimation of filament temperature and adhesion development in fused deposition techniques. Journal of Materials Processing Technology, 245, 167-179. https://doi.org/10.1016/i.jmatprotec.2017.02.026

14. Abbott, A. C., Tandon, G. P., Bradford, R. L., Koerner, H., \& Baur, J. W. (2018). Process-structureproperty effects on ABS bond strength in fused filament fabrication. Additive Manufacturing, 19, 29-38. https://doi.org/10.1016/j.addma.2017.11.002

15. Grabowik, C., Kalinowski, K., Ćwikła, G., Paprocka, I., \& Kogut, P. (2017). Tensile tests of specimens made of selected group of the filament materials manufactured with FDM method. MATEC Web of Conferences, 112, 4017. https://doi.org/10.1051/matecconf/201711204017

16. ASTM: D638 tensile testing standard 
17. Kuznetsov, V.; Solonin, A.N.; Urzhumtsev, O.D.; Schilling, R.; Tavitov, A.G. Strength of PLA Components Fabricated with Fused Deposition Technology Using a Desktop 3D Printer as a Function of Geometrical Parameters of the Process. Polymers 2018, 10, 313

18. https://github.com/daid/LegacyCura

19. http://shop.bondtech.se/en/extruders/bondtech-qr-30-universal.html

20. http://3dsolex.com/product-category/ultimaker-kits/

21. https://www.flir.com/products/flir-tools/

22. Kishore, V., Ajinjeru, C., Nycz, A., Post, B., Lindahl, J., Kunc, V., \& Duty, C. (2017). Infrared preheating to improve interlayer strength of big area additive manufacturing (BAAM) components. Additive Manufacturing, 14, 7-12. https://doi.org/10.1016/J.ADDMA.2016.11.008

23. Go, J., \& Hart, A. J. (2017). Fast Desktop-Scale Extrusion Additive Manufacturing. Additive Manufacturing, 18, 276-284. https://doi.org/10.1016/j.addma.2017.10.016

24. Song, Y., Li, Y., Song, W., Yee, K., Lee, K. Y., \& Tagarielli, V. L. (2017). Measurements of the mechanical response of unidirectional 3D-printed PLA. Materials and Design, 123, 154-164. https://doi.org/10.1016/j.matdes.2017.03.051 